\title{
金属离子响应型荧光传感分子的设计原理及研究进展
}

\author{
张鹏张有明林奇 姚虹魏太保* \\ (西北师范大学化学化工学院 教育部生态环境相关材料重点实验室 甘肃省高分子材料重点实验室 兰州 730070)
}

\begin{abstract}
摘要 荧光传感凭借其高灵敏度、可实现远程监测和实时性等优越性而广受关注，在离子识别中常被用于离子识别信 号的输出. 随着主客体化学的迅速发展, 许多具有良好性能的离子响应型荧光探针相继被报道, 从分子内电荷转移 (ICT)、光诱导的电子转移(PET)、苂光共振能量转移(FRET)、激发态分子内质子转移(ESIPT)、激基缔合物的生成/消失、 螯合作用导致的荧光增强(CHEF)等不同机理对荧光传感型离子识别受体的设计思路进行了理论阐释, 归纳总结了近 5 年来相关文献报道, 阐述了其研究现状和研究进展, 并展望了该领域的研究方向.

关链词 荧光传感; 离子识别; 分子内电荷转移(ICT); 光诱导的电子转移(PET); 荧光共振能量转移(FRET); 激发态分 子内质子转移(ESIPT); 激基缔合物; 荧光增强(CHEF)
\end{abstract}

\section{Principle and the Research Progress of Fluorescent Chemosensors for Cations Recognition}

\author{
Zhang, Peng Zhang, Youming Lin, Qi Yao, Hong Wei, Taibao* \\ (Key Laboratory of Eco-Environment-Related Polymer Materials, Ministry of Education, Key Laboratory of \\ Polymer Materials of Gansu Province, College of Chemistry and Chemical Engineering, \\ Northwest Normal University, Lanzhou 730070)
}

\begin{abstract}
Fluorescent chemosensors received more and more attention because these kinds of chemosensors possess a lot of advantages such as high sensitivity, realize tele-monitor and real-time detection. It was also used as signal output in ion recognition. With the rapid development of host-guest chemistry, a series of fluorescent sensors with good properties have been reported. In this review the research progress of fluorescent chemosensors in terms of recognition principle for ion recognition in resent five years was briefly reviewed based on intramolecular charge transfer (ICT), photoinduced electron transfer (PET), fluorescence resonance energy transfer (FRET), excited-state intramolecular proton transfer (ESIPT), monomer-excimer (EM) and chelation-enhanced fluorescence (CHEF), etc. The developing orientation for further research is presented.

Keywords fluorescent sensor; ion recognition; intramolecular charge transfer (ICT); photoinduced electron transfer (PET); fluorescence resonance energy transfer (FRET); excited-state intramolecular proton transfer (ESIPT); monomer-excimer; chelation-enhanced fluorescence (CHEF)
\end{abstract}

分子识别是超分子化学研究的核心内容之一, 是指 发生的主客体之间的一种特殊的、专一的相互作用, 主 要包括阴阳离子识别、中性分子识别和生物大分子识别, 随着超分子化学的迅速发展, 分子识别在医药学、催化 领域、生物细胞和环境科学中也有着举足轻重的作用. 离子识别作为分子识别的主要部分, 倍受科研工作者的 关注, 它主要是指一个底物分子和一个受体离子各自在
某特殊的部位具有某些结构, 适合于彼此成键的最佳条 件，互相选择对方结合在一起，从而导致受体分子报告 基团的光谱特性(紫外吸收或荧光)发生变化的一个过 程，离子识别过程需要作用物与受体之间达到力场互补 及空间匹配, 被科学家形象的称之为钥匙与锁的相互关 系，同时是一种超分子信息的处理过程，也是自组装高 级结构的重要途径之一.

\footnotetext{
*E-mail: weitaibao@126.com

Received February 28, 2014; revised March 18, 2014; published online April 2, 2014.

Project supported by the National Natural Science Foundation of China (Nos. 21064006, 21161018, 21262032), the Program for Changjiang Scholars and Innovative Research Team in University of Ministry of Education of China (No. IRT1177) and the Natural Science Foundation of Gansu Province (No. 1010RJZA018).

国家自然科学基金(Nos. 21064006，21161018，21262032)、甘肃省自然科学基金(No. IRT1177)及教育部长江学者和创新团队发展计划(No. 1010RJZA018)资助项目.
} 
光化学传感由于其可观测性, 常用于离子识别的信 号输出中, 光信号输出形式主要包括紫外-可见吸收、荧 光、光散射、光反射和化学发光. 相比其他光化学传感 形式而言, 荧光传感凭借其高灵敏度、可实现远程监测 和实时性等优越性而广受瞩目, 在离子识别中倍受科研 工作者的关注.

通常荧光传感器包含两个单元, 识别基团和荧光基 团, 二者通过连接臂或直接相连在同一共轭体系中. 当 识别基团与离子结合时, 苂光团内部的光物理特性受到 影响, 导致荧光信号的输出形式发生变化, 如苂光强度 (量子产率)的变化、荧光峰位置的移动、荧光寿命的增 减及新荧光峰的出现, 从而达到对客体离子的识别目 的. 荧光可以起到信息转化的作用, 即将主客体的识别 信息转化为光学信号, 可以直接明了地反应出主体分子 对客体离子的识别过程. 荧光识别的主要设计机理有分 子内电荷转移 (ICT)、光诱导的电子转移(PET)、苂光共 振能量转移(FRET)、激发态分子内质子转移(ESIPT)、 激基缔合物的生成及螯合作用导致的荧光增强(CHEF) 等 ${ }^{[1 \sim 8]}$. 这些机理均散布在近年来的文献当中, 系统性 的归纳总结尚未见报道, 下面我们将对上述机理做简要 的阐释, 并结合本实验室的具体工作及相关文献报道介 绍苂光传感在离子识别中的研究进展.

\section{1 分子内电荷转移}

分子内电荷转移(Intramolecular Charge Transfer, ICT) 是常见的光物理现象, 也是植物进行光合作用的必 经过程. 基于 ICT 机理的苂光传感分子中, 电子给体和 电子受体一般通过 $\pi$ 体系相连接, 构成了 $\mathrm{D}-\pi-\mathrm{A}$ 共轭体 系. 分子在激发态时发生分子内电子转移, 构成负电荷 的分离, 从而形成了分子内电荷转移态.

\subsection{ICT 型传感器的识别机理}

ICT 型荧光探针一般通过分子内电荷转移(受体单 元接收电子, 给体单元提供电子), 形成了一种电荷分 离的状态, 即 $\mathrm{D}^{+}-\pi-\mathrm{A}^{-}$. 处于激发态分子内电荷转移态 是不稳定的, 可以通过正负电荷的复合而回到基态, 若 该过程为辐射跃迁, 往往伴随着电荷转移 $(\mathrm{CT})$ 荧光发 射. 分子内电荷转移稳定态受外界环境的影响较大, 因 而受到客体离子作用时, 其 CT 发射光谱会发生变化, 能稳定正负电荷分离的客体会降低电荷转移态的能量, 从而导致 $\mathrm{CT}$ 荧光光谱红移, 相反则会导致 $\mathrm{CT}$ 荧光光谱 蓝移.

ICT 型荧光传感器与金属离子的结合过程如图 1 所 示, 当金属离子与荧光团的电子给体作用时, 电荷转移 发生变化, 导致 ICT 光性能的变化. 如果金属离子的加 入导致电子受体的吸电子能力增强, 可以使传感分子紫
外-可见吸收光谱红移，荧光发射光谱则表现为长波长 荧光增强和短波长苂光减弱. 相反, 如果金属离子的加 入导致电子给体的供电子能力减弱, 可以使传感分子紫 外-可见吸收光谱蓝移, 荧光发射光谱则表现为长波长 荧光减弱和短波长荧光增强. 据此可以由单一荧光峰的 增强或减弱来识别金属离子, 也可由两个苂光峰的比值 来检测阳离子的存在. 后者可消除由于激发光源强度波 动、荧光传感分子的浓度和荧光试剂光漂白等外在因素 造成的影响.

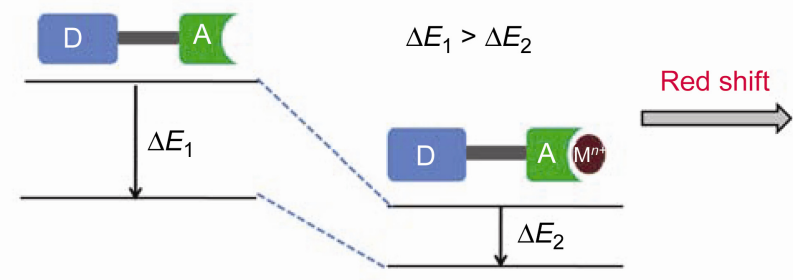

(a) Interaction with acceptor

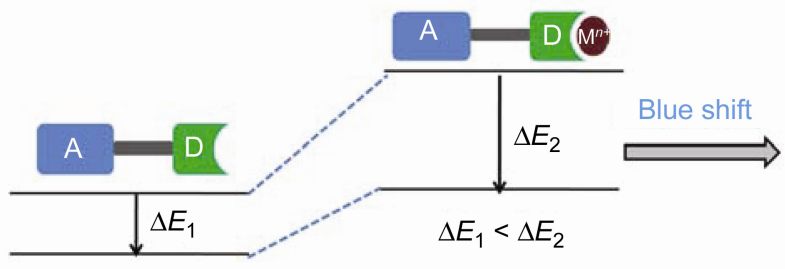

(b) Interaction with donor

图 1 基于 ICT 过程的离子识别机理

Figure 1 Ion recognition mechanism based on ICT progress

\section{2 基于 ICT 过程的离子识别研究}

把离子识单元引入 ICT 苂光体的电子给体或受体 中, 利用离子结合后对电子给体或受体氧化还原电位的 影响, 导致 ICT 荧光体发光行为的改变, 并且通过明显 的苂光信号变化(荧光强度的改变和苂光发射峰的移动) 指示该过程. 2009 年 $\mathrm{He}$ 等 ${ }^{[9]}$ 设计合成具有电荷转移性质 的受体分子 1 (Chart 1), 在 $\mathrm{DMSO} / \mathrm{H}_{2} \mathrm{O}$ 的混合溶剂 $\left(\mathrm{DMSO} / \mathrm{H}_{2} \mathrm{O}, V: V=1: 9, \mathrm{pH}=7.4\right)$ 中, $\mathrm{Zn}^{2+}$ 的加入可以 使其 $544 \mathrm{~nm}$ 出的苂光显著增强, 其它共存阳离子对 $\mathrm{Zn}^{2+}$ 识别过程干扰甚小, 有效地实现了 $\mathrm{nmol} \cdot \mathrm{L}^{-1}$ 浓度级 对 $\mathrm{Zn}^{2+}$ 的传感. 该荧光变化是由 $\mathrm{Zn}^{2+}$ 与 $\mathrm{N}$ 原子配位, 其 供电子能力减弱而造成的.

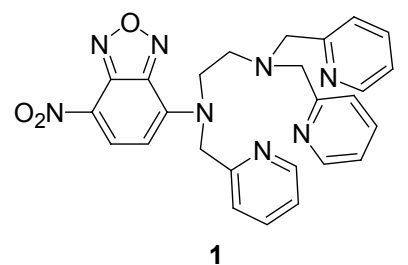

Chart 1 
2010 年 Shyamaprosad 课题组 ${ }^{[10]}$ 设计合成了基于 ICT 机理的受体分子 2 (Eq. 1), 根据其与金属离子的配 位能力差异而选择性识别 $\mathrm{Cu}^{2+}$, 该识别过程分为两步 进行, 当加入 $10 \mu \mathrm{mol}$ 的 $\mathrm{Cu}^{2+}$ 时, $\mathrm{N}$ 原子与 $\mathrm{Cu}^{2+}$ 配位, 吸 收光谱红移颜色由无色变为红色, 随着 $\mathrm{Cu}^{2+}$ 量的加大, 发生去质子作用, 荧光团的电负性增强, 短波长荧光减 弱, 长波长苂光增强, 同时颜色变为蓝色, 实现了对 $\mathrm{Cu}^{2+}$ 的比色荧光双通道识别(Eq. 1).

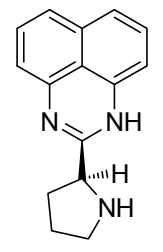

2
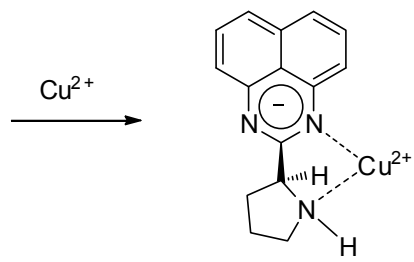

(1)

$\mathrm{Li}$ 等 ${ }^{[11]}$ 以杂冠醚为识别位点, 设计合成了近红外 传感器分子 3 (Chart 2), 它能够选择性结合 $\mathrm{Hg}^{2+}, \mathrm{Hg}^{2+}$ 与 $\mathrm{N}, \mathrm{O}$ 和 $\mathrm{S}$ 杂原子配位, 减弱了分子内电荷转移能力, 长波长荧光几乎猝灭, 对 $\mathrm{Hg}^{2+}$ 的最低检测线可达 $1.1 \times$ $10^{-6} \mathrm{~mol} \cdot \mathrm{L}^{-1}$, 而其它共存阳离子对 $\mathrm{Hg}^{2+}$ 的识别不造成 干扰.

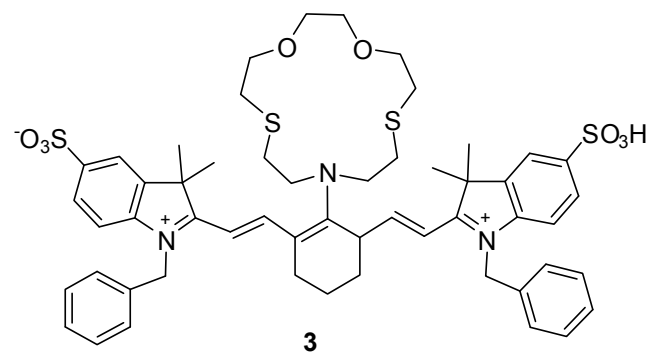

Chart 2

Taki 等 ${ }^{[2]}$ 以香豆素基团为荧光发色团, 以氮烷基吡 啶为结合位点, 合成了基于 ICT 机理的识别受体 $\mathbf{4}$ (Chart 3), 在缓冲体系中实现了对 $\mathrm{Cd}^{2+}$ 的识别, 配位作
用导致其荧光发射峰蓝移, EDTA 的加入可以使荧光恢 复，说明在缓冲体系中 4 对 $\mathrm{Cd}^{2+}$ 的识别是可逆的. 同年, Govindaraju 课题组 ${ }^{[13]}$ 以香豆素基团为苂光发色团, 引 入 2,2-联吡啶和三氮唑为结合位点, 合成化合物 $\mathbf{5}$, 化 合物 5 单一选择性识别 $\mathrm{Al}^{3+}, 440 \mathrm{~nm}$ 处荧光由 $\mathrm{OFF}$ 到 $\mathrm{ON}$ ，其最低检测线可达 $1.0 \times 10^{-7} \mathrm{~mol} \cdot \mathrm{L}^{-1}$.<smiles>CC1=CC(=O)OC2C=C(NCCNCCN(Cc3ccccn3)Cc3cccc(CN)n3)C=CC12</smiles><smiles>O=C1OC2C=CC=CC2C=C1C(=O)N1CCCC1Cn1cc(-c2cccc(-c3ccccn3)n2)nn1</smiles>

\section{Chart 3}

2012 年 $\mathrm{Li}$ 课题组 ${ }^{[14]}$ 设计合成了基于扭曲的分子内 电荷转移(Twisted Intramolecular Charge Transfer, TICT) 机理的 D-A-D 型离子识别受体化合物 6 (Eq. 2), 实验发 现该受体可以作为近红外识别 $\mathrm{Hg}^{2+}$ 的荧光传感器, 在 丙酮和水 $1: 1$ 体系中, 主体化合物在 $592 \mathrm{~nm}$ 处有最大 吸收, 而在 $640 \mathrm{~nm}$ 的苂光发射非常微弱, 主要是由于供 电子基团对发色团扭曲的分子内电荷转移作用所致，当 加入 1 倍量的 $\mathrm{Hg}^{2+}$ 之后其最大吸收蓝移至 $566 \mathrm{~nm}$, 溶 液颜色由蓝色变为紫色, $\mathrm{Hg}^{2+}$ 与 $\mathrm{N}$ 原子配位作用阻碍了 其 TICT 作用, 致使荧光增强 110 倍, 发射出亮红色荧光.

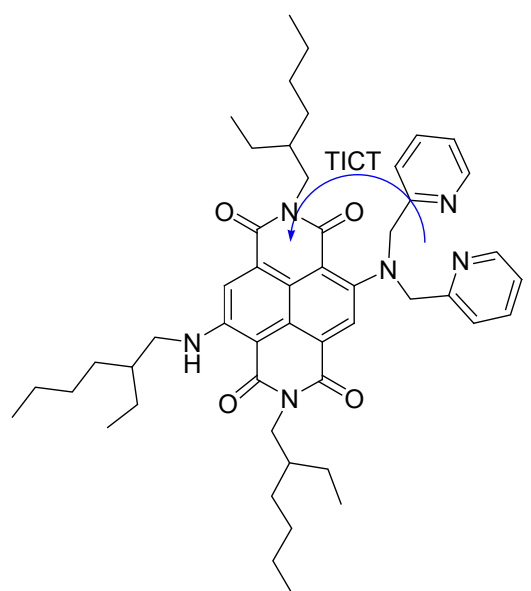

6

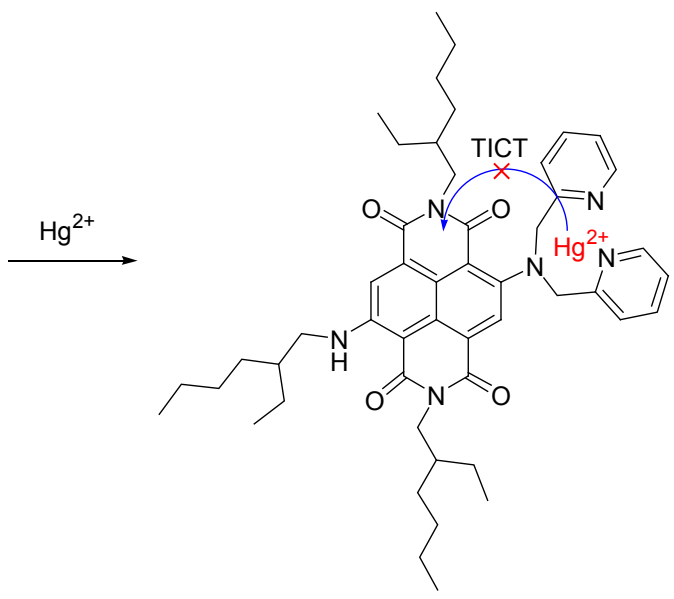


刘伟生等 ${ }^{[15]}$ 以荟二酰亚胺为苂光信号基团, 以酰 胺基团为结合位点设计合成了荧光传感分子 7 (Eq. 3), 实验表明在 $99.5 \%$ 的含水体系中该受体可选择性识别 $\mathrm{Hg}^{2+}$, 无论是录的各类无机盐还是有机录都可以使受体 分子的酰胺键断裂, 具有吸电子性能的酯基消失, 使得 氨基供电子能力大大增强, 吸收光谱有明显的红移, 荧 光光谱则表现为短波长发射减弱, 长波长发射增强, 对 $\mathrm{Hg}^{2+}$ 的最低检测线可达 $4.9 \mathrm{nmol} \cdot \mathrm{L}^{-1}$.

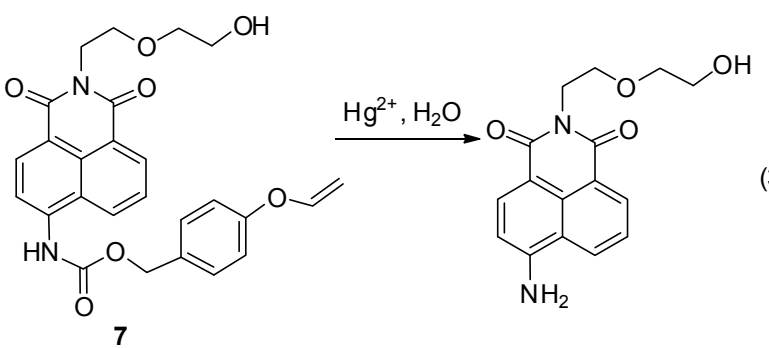

Feng 等 ${ }^{[16]}$ 以咔唑为信号报告基团, 以共轭延伸的 吡定作为识别位点, 设计合成了一系列 Donor-Acceptor 体系的离子识别受体 $8 \sim 11$ (Chart 4), 由于吡啶氮原子 的配位能力较强, 该系列识别受体化合物对许多金属离 子均有响应, 其中 $\mathrm{Pb}^{2+}$ 离子的加入可以使受体分子 8 的 供电子体系供电子能力增强, 从而导致其长波长荧光 (600 nm)增强, 短波长苂光(440 nm) 降低; 在 9 中加入 $\mathrm{Pb}^{2+}$ 使其在 $450 \mathrm{~nm}$ 处的苂光几乎淬灭; 同样地, 往 $\mathbf{1 0}$ 中加入 $\mathrm{Pb}^{2+}$ 可以使 $530 \mathrm{~nm}$ 处的荧光急剧减弱; 受体化 合物 11 在 $\mathrm{Pb}^{2+}$ 作用下 $530 \mathrm{~nm}$ 处苂光峰降低, 但是在 $\mathrm{Cu}^{2+}$ 作用下其荧光峰完全猝灭. TD-DFT 计算进一步考 察了受体分子对不同金属离子的结合能力, 其结果与所 得的光谱性质实验数据完全吻合.
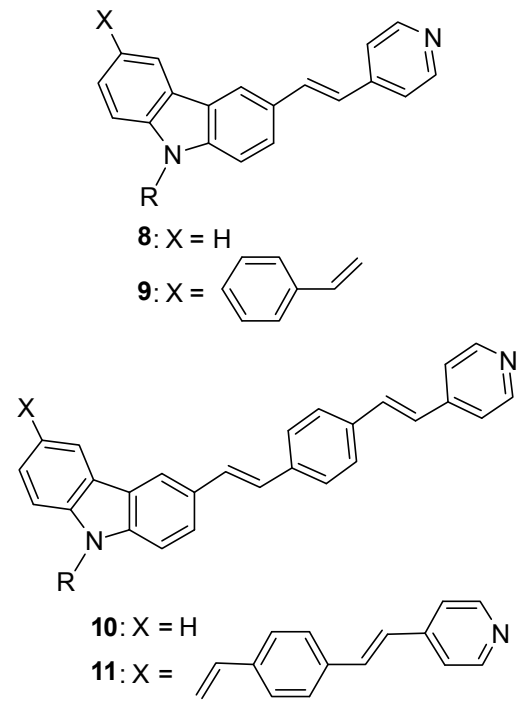

Chart 4

2013 年 Shyamaprosad 课题组 ${ }^{[17]}$ 报道了基于 ICT 机
理的钳形苂光传感分子 $\mathbf{1 2}$ (Chart 5), 在乙腈和水混合体 系中(乙腈/水, $V: V=1: 1)$, 选择性地结合 $\mathrm{Hg}^{2+}$, 当加 入 $\mathrm{Hg}^{2+}$ 浓度较低时, 以 $1: 1$ 的比例结合, $\mathrm{Hg}^{2+}$ 与四个 $\mathrm{N}$ 原子配位形成夹心状配合物; 随着 $\mathrm{Hg}^{2+}$ 量的增加, 传感 分子 12 与 $\mathrm{Hg}^{2+}$ 以 $1: 2$ 比例络合, 该络合作用导致紫外 -可见吸收光谱红移, 苂光 CT 发射峰降低, ET 发射峰增 强. 12 与 $\mathrm{Hg}^{2+}$ 的结合稳定常数可达 $1.7 \times 10^{5} \mathrm{~L} \cdot \mathrm{mol}^{-1}$, 其它共存阳离子对其选择性识别 $\mathrm{Hg}^{2+}$ 不造成干扰. 彭 孝军等 ${ }^{[18]}$ 依据 ICT 机理设计合成了双足的酰胺类离子 识别受体 13 , 以荟酰亚胺为荧光团, 借助 $\mathrm{N}$ 与 $\mathrm{O}$ 原子的 配位能力选择性检测 $\mathrm{Cu}^{2+}, \mathbf{1 3}$ 与 $\mathrm{Cu}^{2+}$ 的配位导致氨基 对苂光团的供电子能力降低，苂光发射峰蓝移，量子产 率降低, 由于受体分子水溶性较好, 可用于活体细胞中 $\mathrm{Cu}^{2+}$ 的检测.

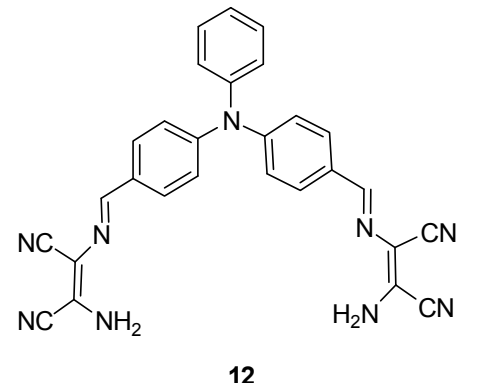

Chart 5

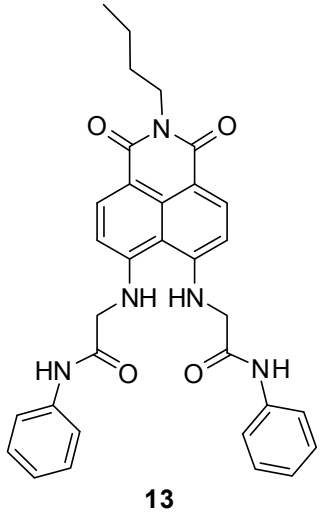

13
Subhajit 研究小组 ${ }^{[19]}$ 报道了双足钳形的离子识别受 体 14 (Chart 6), 依据 $\mathrm{Hg}^{2+}$ 的亲硫性引入硫羰基作为结 合位点, 引入酯基和磺酸基团来增强受体分子的水溶 性. 实验发现 14 在甲醇和水的混合体系中对 $\mathrm{Hg}^{2+}$ 选择 性识别, $\mathrm{Hg}^{2+}$ 与 $\mathrm{S}$ 原子和咪唑环 $\mathrm{N}$ 配位, 降低其供电子 能力，导致荧光发射明显蓝移，荧光发射强度增加 19 倍，苂光颜色由红色变为亮黄色. 为了探讨其实际应用 性能，作者在活体生物中做了对 $\mathrm{Hg}^{2+}$ 的检测，并制备了 $\mathrm{Hg}^{2+}$ 检测试纸, 说明该传感器具有良好的应用性能. 在 抗干扰实验中, 同样具有亲硫性的 $\mathrm{Cu}^{2+}$ 对其识别造成 了一定程度的干扰, 但总体不影响对 $\mathrm{Hg}^{2+}$ 的识别.

Kim 等 ${ }^{[20]}$ 合成了一系列噻唑取代的香豆素类识别 受体 15 17 (Chart 6), 对比发现, 在 DMSO 的含水体系 中, 15 和 16 均对 $\mathrm{Cu}^{2+}$ 有较好的识别性能, 而 17 几乎不 响应，说明羟基参与了与 $\mathrm{Cu}^{2+}$ 的配位. 相比 15 和 16 而 言，受体 16 含有氮烷基的供电子基团，其荧光响应效果 更好，在紫外光照射下达到了裸眼检测效果，因此作者 以 16 为研究对象进行了 $\mathrm{Cu}^{2+}$ 识别研究, $\mathrm{Cu}^{2+}$ 的加入使 着基发生去质子化作用, 并与 $\mathrm{N}, \mathrm{O}$ 杂原子配位，导致吸 
收光谱红移, 溶液颜色加深, 同时 $495 \mathrm{~nm}$ 的荧光发射猝 灭，实现了对 $\mathrm{Cu}^{2+}$ 的紫外-荧光双通道裸眼检测.

同年，韩国科学家 Lee 等 ${ }^{[21]}$ 以氮烷基取代的萘磺酸 为苂光发色团，手性氨基酰胺为结合位点，设计合成了 一系列带有手性基团的单足、双足酰胺类离子识别受体 分子 18 21 (Chart 7), 实验发现, 18 和 21 对所测金属离 子响应能力差，化合物 19 在 $100 \%$ 水溶液中对 $\mathrm{Cu}^{2+}$ 有明 显响应, $\mathrm{Cu}^{2+}$ 的加入使其苂光明显减弱, 但无法达到猝 灭. $100 \%$ 水溶液中化合物 20 在 $525 \mathrm{~nm}$ 处有很弱的苂光, 加入 $\mathrm{Hg}^{2+}$ 后荧光增强并蓝移至 $500 \mathrm{~nm}$, 作者通过发射 光谱数据、质谱、红外和核磁的表征手法证实 $\mathrm{Hg}^{2+}$ 与受 体分子中的 3 个氮原子同时配位. 该传感器通过 ICT 过 程实现了纯水相中对 $\mathrm{Hg}^{2+}$ 的识别, 其它共存离子对其 识别过程不造成干扰, 并且实现了血液中 $\mu \mathrm{mol} \cdot \mathrm{L}^{-1}$ 级 的 $\mathrm{Hg}^{2+}$ 实时检测.

2013 年 $\mathrm{He}$ 等 ${ }^{[22]}$ 以氟嗍吡咯为荧光报告基团, 设计 合成了离子识别受体 22 和 23 (Chart 8). 其中化合物 22 可以在乙腈中选择性识别 $\mathrm{Zn}^{2+}, \mathrm{Zn}^{2+}$ 的加入使其在 586 $\mathrm{nm}$ 的最大吸收峰蓝移到 $563 \mathrm{~nm}$, 并在 571, 452 和 350 $\mathrm{nm}$ 出现等吸收点, $624 \mathrm{~nm}$ 的荧光发射峰减弱, $572 \mathrm{~nm}$ 处 的发射峰增强, Job 曲线表明 22 与 $\mathrm{Zn}^{2+}$ 以 1: 1 的比例 结合, 该过程主要是由于 $\mathrm{Zn}^{2+}$ 与 $\mathrm{N}, \mathrm{O}$ 原子配位降低了 其供电子能力. 而化合物 23 则对 $\mathrm{Cd}^{2+}$ 有很好的选择性 识别效果, 化合物 23 和 $\mathrm{Cd}^{2+}$ 以 $1: 2$ 的比例结合, 使其 在 $666 \mathrm{~nm}$ 的苂光峰增强 100 倍, 实现了对 $\mathrm{Cd}^{2+}$ 的 OFF-ON 型苂光响应.

2013 年, 本课题组 ${ }^{[23]}$ 以萘环作为荧光信号基团，以 $\mathrm{C}=\mathrm{N}$ 和 $\mathrm{OH}$ 作为离子结合位点, 设计合成了双萗环的 $\mathrm{Hg}^{2+}$ 苂光传感分子 24 (Chart 9), 在 DMSO 溶液中, 主体 分子的两个菜环不在同一平面, 其最大吸收峰在 475 $\mathrm{nm}$, 在 $415 \mathrm{~nm}$ 处有很弱的苂光发射峰, 加入 $\mathrm{Hg}^{2+}$ 后, 由于 $\mathrm{Hg}^{2+}$ 的配位作用导致两个菜环处于同一平面，且 共轭间断, 实现了由 TICT 到 ICT 的转化, 在光谱上表 现为最大吸收蓝移至 $356 \mathrm{~nm}$, 溶液颜色由黄色转变为 无色, $415 \mathrm{~nm}$ 的发射峰增强 20 倍, 发射出很强的蓝色荧 光. 该传感分子实现了对 $\mathrm{Hg}^{2+}$ 双通道裸眼检测. 2014年, 该课题组 ${ }^{[24]}$ 按照同样的传感机理以喹啉为苂光团，设 计合成了化合物 25 (Chart 9), 在 DMSO 和水混合体<smiles>COC(=O)C(Cc1cnn(S(=O)(=O)c2cccc3c(N(C)C)cccc23)c1)NC(=S)SCc1cc(C(C)(C)C)cc(CSC(=S)NC(Cc2cnn(S(=O)(=O)c3cccc4c(N(C)C)cccc34)c2)C(=O)OC)c1OC</smiles><smiles>O=C1OC2C=CC=CC2C=C1c1csc(-c2ccccc2O)n1</smiles>

15<smiles>CCN(CC)C1=CC2OC(=O)C(c3csc(-c4ccccc4O)n3)=CC2C=C1</smiles><smiles>CCN(CC)C1=CC2OC(=O)C(c3csc(-c4ccccc4)n3)=CC2C=C1</smiles>

17

Chart 6

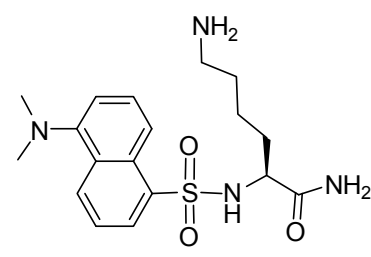

18

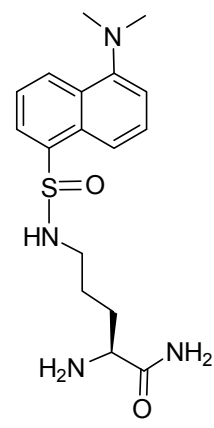

19

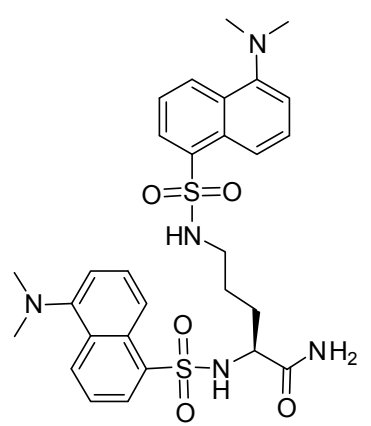

20<smiles>CN(C)c1cccc2c(S(=O)(=O)NCCCC(NS(=O)(=O)c3cccc4c(N(C)C)cccc34)C(=O)O)cccc12</smiles>

21

Chart 7 


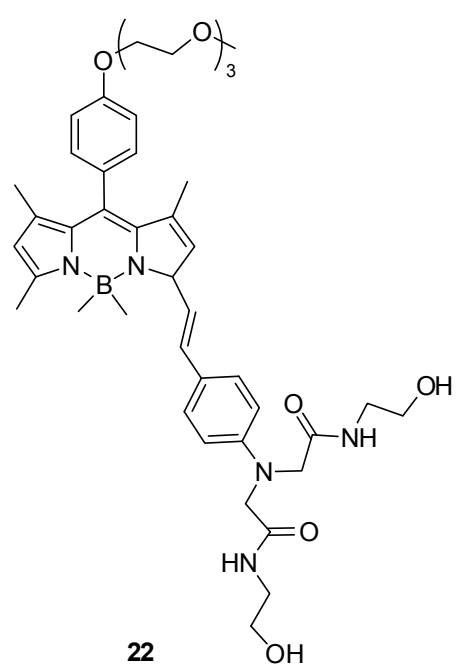<smiles>COc1ccc(C2=C3C(C)=CC(C=Cc4ccc(N(CC(=O)NCCO)CC(=O)NCCO)c(N(CC(=O)NCCO)CC(=O)NCCO)c4)N3B(C)n3c(C)cc(C)c3C2)cc1</smiles>

Chart 8

系中 (DMSO/水, $V: V=9: 1), \mathrm{AcO}^{-}$可以使其由 $\mathrm{TICT}$ 到 ICT 转化, $520 \mathrm{~nm}$ 苂光增强, 实现了对 $\mathrm{AcO}^{-}$的选择性 识别, 其最低检测线可达 $4.0 \times 10^{-7} \mathrm{~mol} \cdot \mathrm{L}^{-1}$.

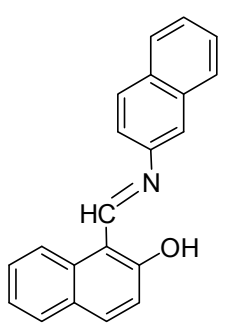

24

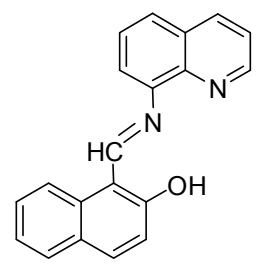

25

\section{Chart 9}

\section{2 光诱导电子转移}

光诱导电子转移(Photoinduced Electron Transfer, PET) 是一种很重要的光物理过程, 基于 PET 机理的苂 光传感分子中, 电子受体与电子给体以 $\sigma$ 键相连, 处于 同一分子当中, 但不是共轭的体系. 也就是说, 连接臂 既使发色团与受体单元联接成为一个整体, 又使它们保 持一定的距离. 近些年来人们对 PET 过程做了大量的研 究, 利用这一过程设计合成了一系列具有很好性质的荧 光化学传感器. 根据荧光打开和荧光关闭的方式检测客 体分子的存在, 可将荧光传感器分为 “ $\mathrm{OFF}-\mathrm{ON}$ ” 型荧 光传感器和 “ON-OFF” 型荧光传感器.

\subsection{PET 型传感器的识别机理}

一般来说, PET 型苂光探针由发色团(荧光团)、连接 臂和受体三部分组成, 苂光团大多是含有大共轭结构的 体系, 例如菜、葱、萠等, 它们是光能的吸收和苂光发 射的场所. 识别功能单元则含有 $\mathrm{N}, \mathrm{O}, \mathrm{S}$ 等杂原子, 可以 很好地结合客体离子. 连接臂的主要作用是将荧光团与
识别单元联接在一起, 并使之相隔一定的距离. PET 型荧 光传感器与客体离子的结合过程如图 2 所示, 受体分子 与客体离子结合之前, 处于激发态的苂光团足以氧化受 体分子，是自身成为一种不能发生荧光的物种，该过程 称为 PET 过程. 与之相对应，如果体系处于弱荧光或无 苂光状态, 当受体与客体结合之后, 其氧化电势提高, 激 发态的荧光团不能氧化受体分子, 阻止了 PET 过程, 导 致体系荧光恢复，这就形成了主体与客体结合后，苂光 由 $\mathrm{OFF}$ 到 $\mathrm{ON}$ 的响应过程. 从前线轨道能量图来讲, 客体 离子不存在时, 受激发的荧光团最高占有轨道 $(\mathrm{HOMO}$ 轨 道)的一个电子跃迁到最低空轨道(LUMO 轨道), 当客体 基团的 HOMO 轨道介于荧光团的 HOMO 轨道和 LUMO 轨道之间时, 其电子可以跃迁到荧光团的 HOMO 轨道, 致使其被激发的 LUMO 轨道的一个电子无法回到基态, 从而导致荧光猝灭, 这就是 PET 过程. 相反, 如果客体的 $\mathrm{HOMO}$ 轨道低于荧光团的 HOMO 轨道时, 其电子无法转 移到苂光团的 HOMO 轨道, 使 PET 过程受阻, 苂光团被 激发的 LUMO 轨道的一个电子回到基态, 荧光团的荧光 得以恢复. 可见基于 PET 机理的识别主要是依据客体对 苂光团发光过程的调控而达到的.

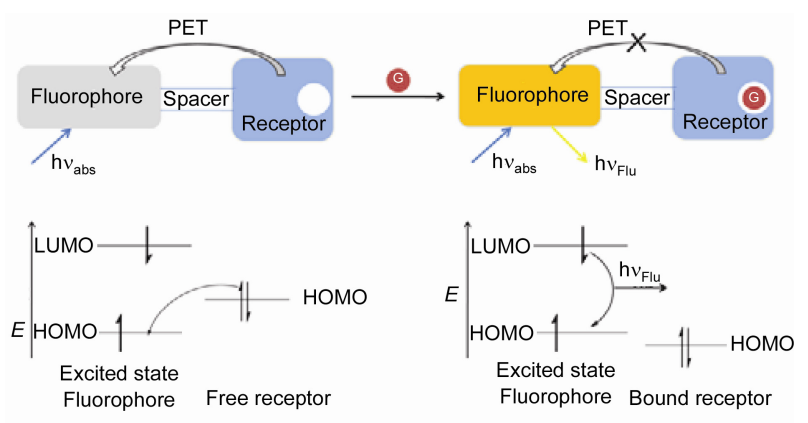

图 2 基于 PET 过程的离子识别机理

Figure 2 Ion recognition mechanism based on PET progress 


\section{2 基于 PET 过程的离子识别研究}

对大多数 PET 苂光传感器来说, 识别基团一般含有 脂肪胺或芳香胺, 通过连接臂与荧光团相连, 受到激发 时 $\mathrm{N}$ 上的孤对电子向苂光团转移, 导致荧光猝灭. 客体 离子存在时与 $\mathrm{N}$ 原子上的孤对电子配位, 电子转移受到 抑制, 苂光恢复. $\mathrm{Xu}$ 等 ${ }^{[25]}$ 引入氟嗍吡咯作为荧光信号 才, 聚酰胺为识别位点, 依据 PET 机理设计合成了识别 受体化合物 26 (Chart 10), 主体化合物由于酰胺基团对 氟嗍吡咯的 PET 作用而本身没有荧光, 加入 $\mathrm{Cd}^{2+}$ 之后 阻碍了其 PET 作用, 导致 $578 \mathrm{~nm}$ 处的吸收光谱降低, $562 \mathrm{~nm}$ 出现一个新的吸收峰, 同时 $570 \mathrm{~nm}$ 处的苂光发 射峰增加 195 倍, 苂光量子产率增加大约 100 倍, 该主 体与 $\mathrm{Cd}^{2+}$ 按 $1: 2$ 的比例结合, 其识别过程不受其它共 存离子的干扰，对 $\mathrm{Cd}^{2+}$ 的最低检测线可达 $6 \times 10^{-7}$ $\mathrm{mol} \cdot \mathrm{L}^{-1}$.

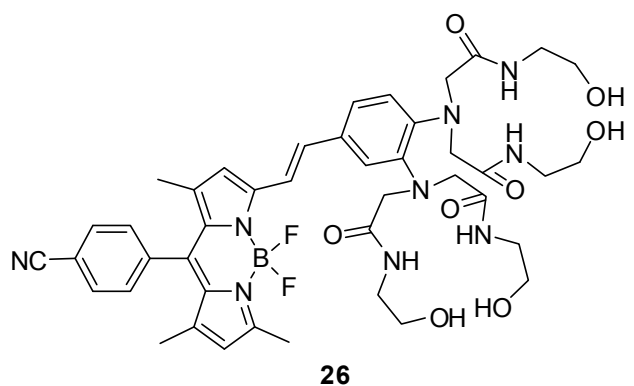

Chart 10

2011 年, 该研究小组 ${ }^{[26]}$ 利用同样的机理(PET 机理) 设计合成了双足的 $\mathrm{Cd}^{2+}$ 识别受体化合物 27 (Chart 11), 该受体在 $90 \%$ 的含水介质中对 $\mathrm{Cd}^{2+}$ 选择性识别, $\mathrm{Cd}^{2+}$ 与 酰胺链上的 $\mathrm{N}, \mathrm{O}$ 原子配位, 阻碍了其光诱导的分子内 电子转移过程, 受激发的电子可以顺利回到基态, 荧光 性质恢复, 其结合比为 $1: 4$, 在光谱上 $\mathrm{Cd}^{2+}$ 的加入使其 在 $664 \mathrm{~nm}$ 的最大吸收峰蓝移至 $638 \mathrm{~nm}, 640 \mathrm{~nm}$ 处出现

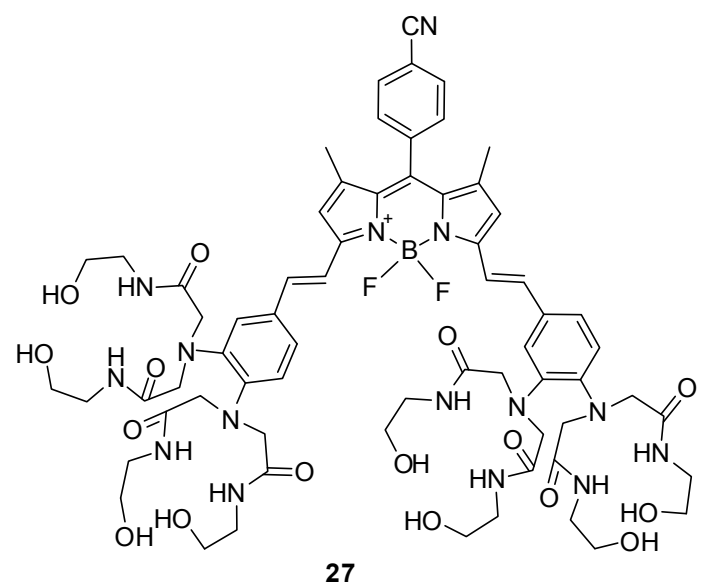

Chart 11
很强的荧光峰, 由于 $\mathrm{Hg}^{2+}$ 具有和 $\mathrm{Cd}^{2+}$ 相似的结构, 因而 该识别过程受到 $\mathrm{Hg}^{2+}$ 的干扰.

同年，他们利用同样的结合位点，以酞菁作为苂光 信号基团，设计合成了基于 PET 机理的 $\mathrm{Cd}^{2+}$ 识别受体

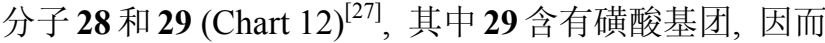
具有较好的水溶性，作者选取化合物 29 在乙腈和水的 混合体系中对 $\mathrm{Cd}^{2+}$ 的识别进行了研究, $\mathrm{Cd}^{2+}$ 的加入使其 在 $793 \mathrm{~nm}$ 处的苂光峰显著增强，发射出红色荧光，实现 了近红外识别, Job 法研究表明主体分子与 $\mathrm{Cd}^{2+}$ 按照 1 : 2 的比例结合, 该识别过程对 $\mathrm{Cd}^{2+}$ 具有很好的选择性, 不受共存离子的干扰.

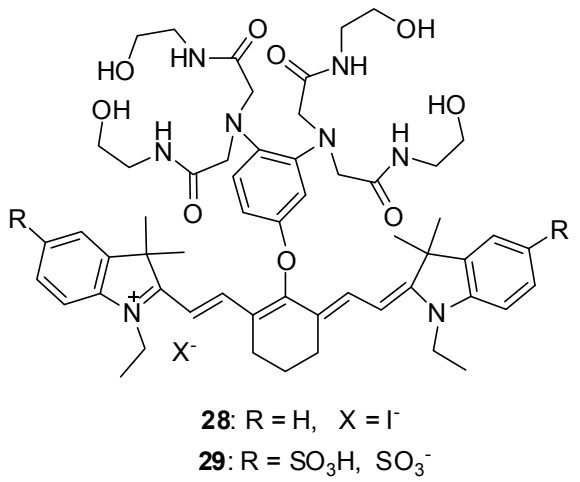

Chart 12

2011 年 Chang 等 ${ }^{[28]}$ 同样以氟硼吡咯为荧光信号基 才, 以含 $\mathrm{N}, \mathrm{S}$ 的杂烷基链作为离子结合位点的荧光传感 分子 30 (Chart 13), 该传感化合物可在缓冲体系中 $(\mathrm{pH}=7.4)$ 对 $\mathrm{Cu}^{2+}$ 选择性响应, 1 equiv. $\mathrm{Cu}^{2+}$ 的加入阻碍 了主体分子的 PET 过程, 导致 $558 \mathrm{~nm}$ 处的荧光发射峰 增强 10 倍, 并且该识别过程不受其它共存离子的影响, Job 曲线表明该受体与 $\mathrm{Cu}^{2+}$ 按 $1: 1$ 的比例结合，传感分 子 30 与 $\mathrm{Cu}^{2+}$ 结合稳定常数可达 $7.2 \times 10^{-12} \mathrm{~mol} \cdot \mathrm{L}^{-1}$, 对 $\mathrm{Cu}^{2+}$ 的最低检测线为 $2 \mu \mathrm{mol} \cdot \mathrm{L}^{-1}$.

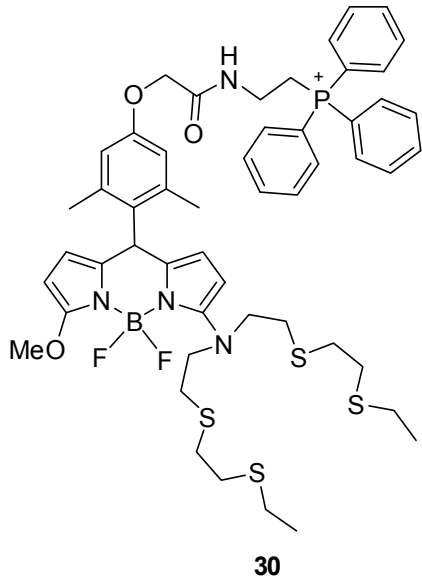

Chart 13

2012 年 Taki 课题组 ${ }^{[29]}$ 同样利用含 $\mathrm{N}, \mathrm{S}$ 的杂烷基链 
作为离子结合位点, 根据 $\mathrm{Hg}^{2+}$ 的亲硫性, 依据 PET 机理 设计合成了菼光传感分子 31 (Chart 14), 实验表明传感 分子 31 对 $\mathrm{Hg}^{2+}$ 具有单一选择性识别作用, 向主体的溶 液中滴加 $\mathrm{Hg}^{2+}$ 可以使 $579 \mathrm{~nm}$ 处苂光打开, 再滴加 EDTA 溶液又可导致荧光猝灭, 说明 $\mathrm{Hg}^{2+}$ 与主体分子以 配位作用结合, 进一步证实了其 PET 过程, 并且实现了 “ON-OFF-ON” 的循环识别过程, 经 Job 曲线法证实主 体与 $\mathrm{Hg}^{2+}$ 按 $1: 1$ 的比列络合, 其最低检测线可低达 $(1.04 \pm 0.05) \times 10^{-16} \mathrm{~mol} \cdot \mathrm{L}^{-1}$.

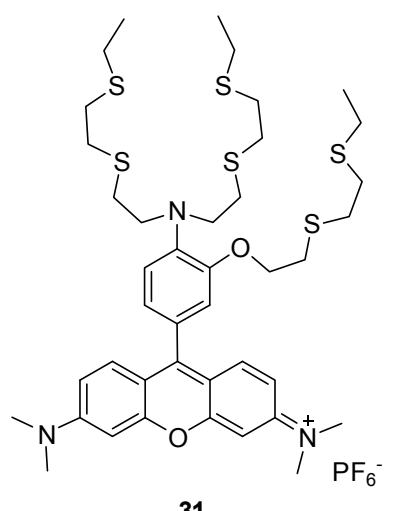

31

Chart 14

2012 年, Zheng 课题组 ${ }^{[30]}$ 以酞菁染料为信号报告基 团, 引入腺嘌呤作为离子识别结合位点, 利用 PET 机理 设计合成了菼光传感分子 32 (Chart 15). 经过实验验证, 该传感分子以 $\mathrm{A}-\mathrm{Ag}^{+}-\mathrm{A}$ 型结合模式实现了对 $\mathrm{Ag}^{+}$的选 择性识别, 向主体化合物的甲醇和水的混合体系中滴加 $\mathrm{Ag}^{+}$, 其 $650 \mathrm{~nm}$ 处苂光发射峰(PET 过程发射峰)降低, $508 \mathrm{~nm}$ 发射(PET 受阻时的发射峰)增强, 实现了对 $\mathrm{Ag}^{+}$ 的近红外苂光响应, Job 曲线在 0.35 处达到顶点, 说明该 主体与 $\mathrm{Ag}^{+}$按 2:1 的比例结合. 再向主体和 $\mathrm{Ag}^{+}$体系中 滴加 $\mathrm{NaOH}$ 溶液, 可以将 $\mathrm{Ag}^{+}$沉淀下来导致荧光猝灭, 实现了 “ON-OFF-ON” 的循环识别过程, 经计算主体对 $\mathrm{Ag}^{+}$的达检测线 $4 \times 10^{-9} \mathrm{~mol} \cdot \mathrm{L}^{-1}$.

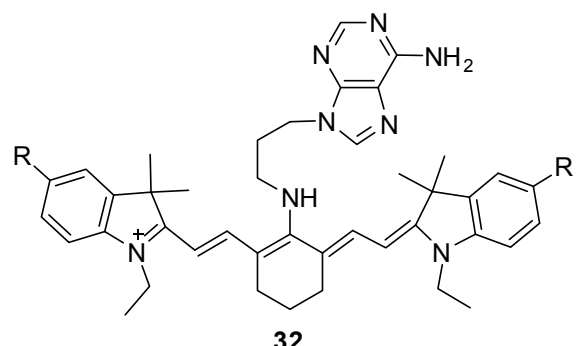

Chart 15

Das 等 ${ }^{[31]}$ 用喹啉 2-甲醛和水合肼反应得到 PET 型离 子识别受体 33 , 光谱实验表明该主体化合物在四氢呋 喃和水的缓冲溶液中 $(V: V=4: 6)$, 于 $\mathrm{Li}^{+}, \mathrm{Na}^{+}, \mathrm{K}^{+}$,
$\mathrm{Cs}^{+}, \mathrm{Ca}^{2+}, \mathrm{Mg}^{2+}, \mathrm{Sr}^{2+}, \mathrm{Ba}^{2+}, \mathrm{Cr}^{3+}, \mathrm{Fe}^{2+}, \mathrm{Co}^{2+}, \mathrm{Ni}^{2+}, \mathrm{Cu}^{2+}$, $\mathrm{Hg}^{2+}, \mathrm{Zn}^{2+}, \mathrm{Cd}^{2+}$ 等多种阳离子中选择性识别 $\mathrm{Hg}^{2+}$ (Eq. 4), $\mathrm{Hg}^{2+}$ 的加入可以导致主体分子两个喹啉环的共平面 性增强, 在紫外-可见光谱上表现为 $330 \mathrm{~nm}$ 的吸收峰 (喹啉环异面时的吸收)降低, $370 \mathrm{~nm}$ 处的吸收峰(喹啉环 的共面时的吸收)增强, 在 $400 \mathrm{~nm}$ 出现 OFF-ON 型苂光 光谱响应, 这是由于 $\mathrm{Hg}^{2+}$ 与 $\mathrm{N}$ 原子配位, PET 过程受阻 而造成的. 抗干扰实验证明该主体对 $\mathrm{Hg}^{2+}$ 的识别具有 很高的选择性, 不受其它共存离子的干扰.

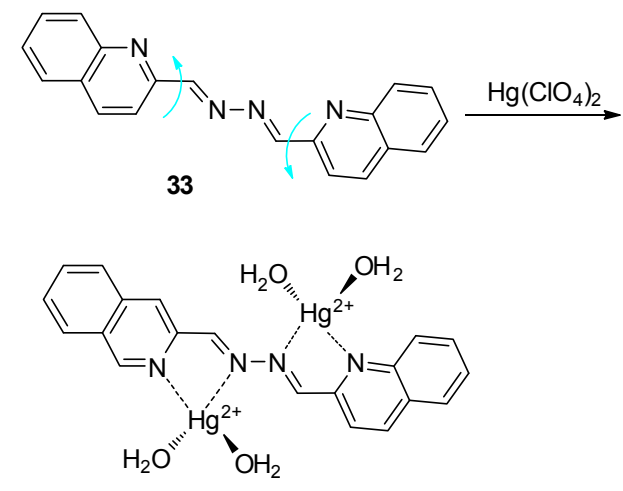

2012 年该课题组 ${ }^{[32]}$ 利用同样的识别机理, 设计合 成了一系列具有刚性结构的连接臂的 $\mathrm{Hg}^{2+}$ 识别受体化 合物 34 36 (Chart 16), 作者以化合物 32 为例进行了光 谱实验, 在 $\mathrm{CHCl}_{3} / \mathrm{CH}_{3} \mathrm{CN}(V: V=1: 4)$ 体系中, 加入 $\mathrm{Hg}^{2+}$ 可使主体在 $385 \mathrm{~nm}$ 的吸收降低, $470 \mathrm{~nm}$ 的吸收增 强, 在 $395 \mathrm{~nm}$ 出现 OFF-ON 的荧光响应, 作者通过单晶 结构展示了基于 PET 机理的 $\mathrm{Hg}^{2+}$ 识别模式.
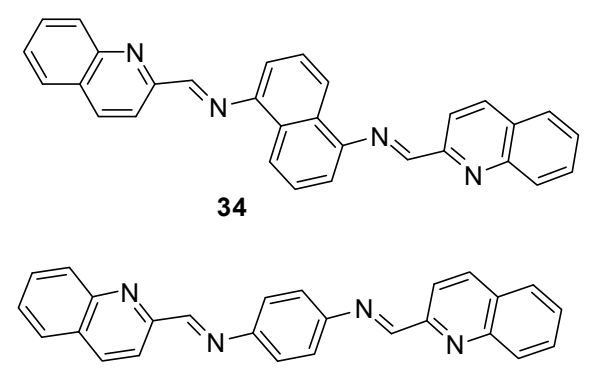

35

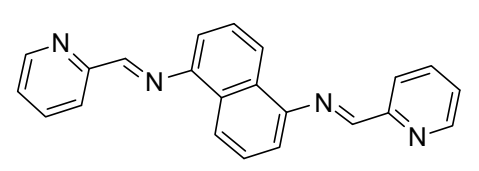

36

\section{Chart 16}

2012 年 Lee 课题组 ${ }^{[33]}$ 以萠为苂光信号报告基团, 引 入手性氨基酸作为离子识别位点, 设计合成了萠磺酰胺 类受体化合物 37 (Chart 17), 该受体分子由于引入了酰 胺基团和磺酰胺基团，从而使其具有较好的水溶性. 作 者在较大含水体系(含水 $95 \%$ 的乙腈水溶液)中进行光谱 
实验，发现在该体系中受体分子对 $\mathrm{Pb}^{2+}$ 有选择识别性 能, 当激发波长为 $342 \mathrm{~nm}$ 时, 在 $380 \mathrm{~nm}$ 处的荧光发射 强度增强 7 倍, Job 曲线在 0.5 处达到顶点, 说明该主体 与 $\mathrm{Pb}^{2+}$ 按 $1: 1$ 的比例结合.

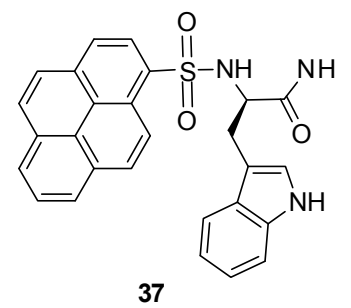

Chart 17

2011 年 Nakamura 等 ${ }^{[34]}$ 用葱作为荧光信号基团, 设 计合成了一系列苯并冠醚类离子识别受体 $38 \sim 40$ (Chart 18), 苂光光谱实验表明该系列化合物在乙腈溶 液中几乎没有荧光, 这归因于冠醚基团对荧光团受激发 后空的 HOMO 轨道的供电子作用, 而在 39 的乙腈溶液 中加入 $\mathrm{Mg}^{2+}$, 可以使其在 $445 \mathrm{~nm}$ 处的荧光打开, 而化 合物 38 和 40 的乙腈溶液对 $\mathrm{Mg}^{2+}$ 没有荧光响应, 这是因 为化合物 39 与 $\mathrm{Mg}^{2+}$ 配位阻碍了 PET 过程.

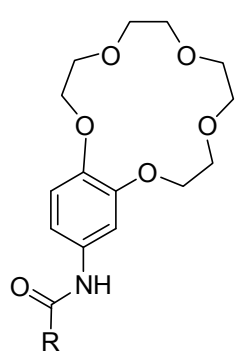

38: $R=$

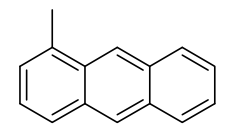

39: $\mathrm{R}=$

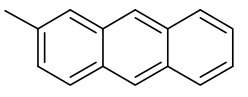

40: $R=$

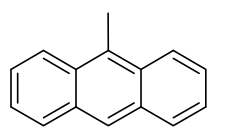

Chart 18

\section{3 荧光共振能量转移}

荧光共振能量转移(Fluorescence Resonance Energy Transfer, FRET)是指一个苂光基团(供体单元)的苂光光 谱与另一个荧光基团(受体单元)的激发光谱相重叠时, 供体苂光分子的激发能诱发受体分子发出荧光, 同时供 体荧光分子自身的荧光强度衰减的光物理过程. 苂光共 振能量转移的强度依赖于供体发射谱和受体激发谱的 重叠程度, 以及供体和受体能量转移的偶极子的相对方 位.

\subsection{FRET 型传感器的识别机理}

荧光共振能量转移是指在两个不同的苂光基团中, 如果一个苂光基团(供体单元)的发射光谱与另一个基团 (受体单元)的吸收光谱有一定的重叠, 当这两个荧光基 团间的距离合适时, 就可观察到苂光能量由供体向受体 转移的现象, 即 FRET 现象. FRET 程度与供、受体分子
的空间距离紧密相关，一般为 7 10 nm 时即可发生 FRET; 随着距离延长, FRET 显著减弱.

FRET 型苂光传感器与客体离子的结合过程如图 3 所示，当客体离子与荧光团相作用时，用前一种基团的 激发波长激发时，可观察到后一个基团发射的荧光. 简 单地说，就是在供体基团的激发状态下由一对偶极子介 导的能量向受体转移的过程, 此过程没有光子的参与, 所以是非辐射的，供体分子被激发后，当受体分子与供 体分子相距一定距离, 且供体和受体的基态及第一电子 激发态两者的振动能级间的能量差相互适应时, 处于激 发态的供体将把一部分或全部能量转移给受体，使受体 被激发, 在整个能量转移过程中, 不涉及光子的发射和 重新吸收. 如果受体荧光量子产率为零, 则发生能量转 移荧光熄灭; 如果受体也是一种荧光发射体, 则呈现出 受体的苂光, 并造成次级苂光光谱的红移.

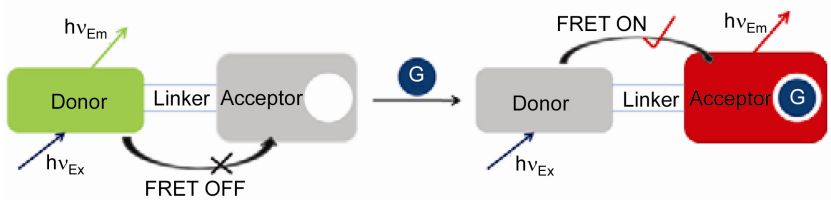

图 3 基于 FRET 过程的离子识别机理

Figure 3 Ion recognition mechanism based on FRET progress

\section{2 基于 FRET 过程的离子识别研究}

FRET 过程中的能量供给体-接受体之间发生有效 能量转移的条件是苛刻的, 主要包括: (1)能量供体的发 射光谱与能量受体的吸收光谱必须重叠, (2)能量供体与 能量受体的荧光生色团必须以适当的方式排列, (3)能量 供体、能量受体之间必须足够接近, 这样发生能量转移 的几率才会高. 此外, 对于合适的供体、受体分子在量 子产率、消光系数、水溶性、抗干扰能力等方面还有众 多的要求, 因此, 要找到一个合适的 FRET 体系是很不 容易的. 由于 FRET 过程可以实现短波长激发诱导长波 长发射这一重要的光物理过程, 科学家们在这方面做了 巨大努力, 实现了荧光共振能量转移给体一受体的设计 合成并取得了很好的结果.

2012 年 Amitava 等 ${ }^{[35]}$ 以荧光共振能量转移(FRET) 机理设计合成了离子识别受体化合物 41 和 42 (Chart 19), 其中化合物 41 以邻苯二酰亚胺基团作为能量给体, 以罗丹明基团作为能量受体，邻苯二酰亚胺基团 530 $\mathrm{nm}$ 处有最大吸收, 而能量受体单元的荧光发射一般在 $550 \mathrm{~nm}$ 处, 由此看来化合物 $\mathbf{4 1}$ 的 Donor 基团的最大吸 收与 Acceptor 的发射有较大程度重合, 符合 FRET 机理 的设计要求. 作者在含水 $50 \%$ 的乙腈体缓冲体系中对离 子识别受体 41 进行了光谱实验, 发现 $\mathrm{Cr}^{3+}$ 和 $\mathrm{Hg}^{2+}$ 可以 导致主体在 $530 \mathrm{~nm}$ 的吸收升高, 溶液颜色由无色变成 
红色, $550 \mathrm{~nm}$ 的荧光明显增强, 出现亮黄苂光, Job 法证 明主体和离子按照 1: 1 的比例结合. 化合物 $\mathbf{4 2}$ 以荟二 酰亚胺基团作为能量给体, 以罗丹明基团作为能量受 体, 同样以苂光共振能量转移机理对 $\mathrm{Cr}^{3+}$ 和 $\mathrm{Hg}^{2+}$ 识别, $\mathrm{Cr}^{3+}$ 和 $\mathrm{Hg}^{2+}$ 的加入可以导致主体在 $550 \mathrm{~nm}$ 出现吸收新 峰, $530 \mathrm{~nm}$ 处 Donor 基团的荧光峰降低, $596 \mathrm{~nm}$ 出现新 的苂光发射峰，该苂光是罗丹明开环后的发射.

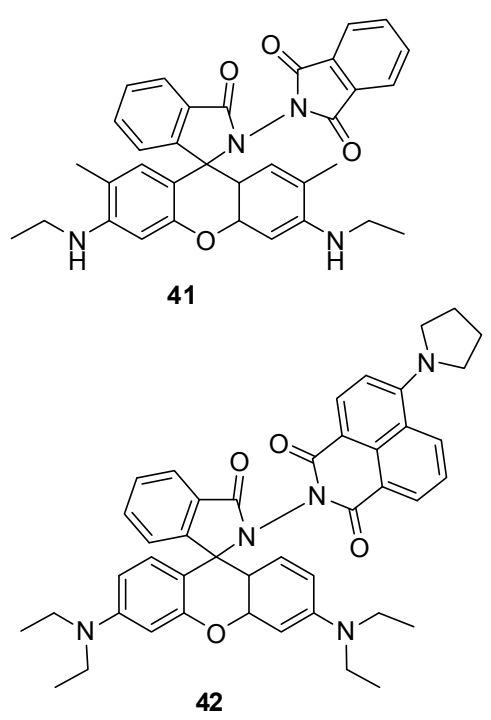

Chart 19

Das 等 ${ }^{[36]}$ 以吲哚衍生物作为能量给体，以罗丹明基 团作为能量受体设计合成了 FRET 型离子识别受体 43 (Chart 20), 在 $80 \%$ 的含水体系中主体化合物本身在 550 $\mathrm{nm}$ 处紫外-可见吸收峰很弱, 加入 $\mathrm{Cu}^{2+}$ 后罗丹明开环, $550 \mathrm{~nm}$ 吸收峰增强, 并且在 $700 \mathrm{~nm}$ 有新的吸收峰出现, 在苂光光谱上 $580 \mathrm{~nm}$ 出现很强的荧光发射峰. 在主体 与 $\mathrm{Cu}^{2+}$ 的混合体系中, 加入 $\mathrm{S}^{2-}$ 可使其吸收光谱和苂光 光谱恢复到原来的状态, 实现苂光 “OFF-ON-OFF” 的 循环, Job 曲线在 0.5 处有顶点说明主体和离子按照 $1: 1$ 的比例结合, 抗干扰实验证明阴、阳离子对该识别过程 不干扰.

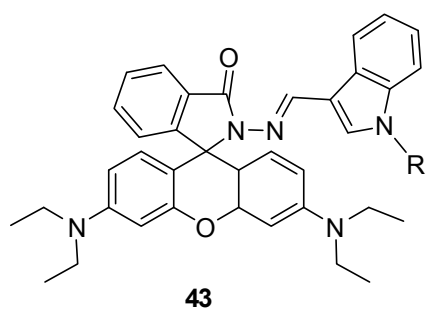

Chart 20

$\mathrm{Zhu}$ 等 ${ }^{[37]}$ 根据 FRET 机理设计合成了离子识别受体 化合物 44 (Chart 21), 该化合物以 2,2-联吡啶作为离子 结合位点, 以罗丹明基团作为能量接受体, 其 Donor 基
团的最大吸收与 Acceptor 的发射有较大程度的重合，适 合 FRET 过程的发生. 光谱实验证明, 加入 $\mathrm{Zn}^{2+}$ 时, $\mathrm{Zn}^{2+}$ 和 2,2-联吡啶的 $\mathrm{N}$ 原子配位，苂光共振能可以从该 配位单元转移到到罗丹明，导致罗丹明开环，在光谱上 表现为 $580 \mathrm{~nm}$ 的吸收峰增强, 溶液颜色由无色变为粉 红色，在 $592 \mathrm{~nm}$ 发射出很强的荧光，苂光颜色由淡绿色 变为很强的橙色.

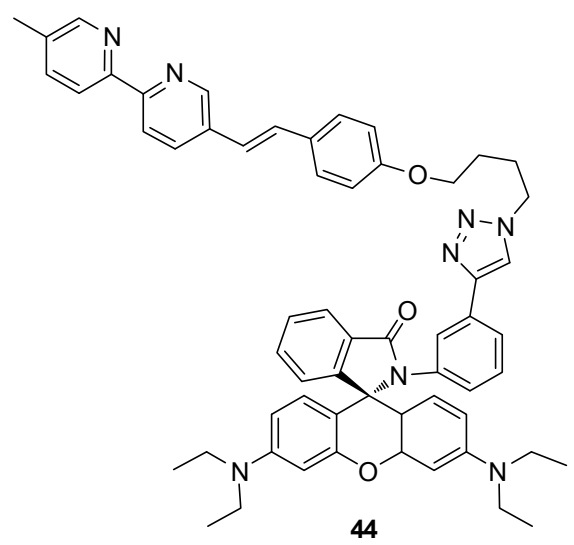

Chart 21

Zhou 等 ${ }^{[38]}$ 以萠作为能量给体，以罗丹明基团作为 能量受体，设计合成了基于 FRET 机理的荧光传感分子 45 和 46 (Chart 22), 萠的亚胺基团 $525 \mathrm{~nm}$ 处有最大吸 收, 而能量受体单元的荧光发射在 $575 \mathrm{~nm}$ 处, 由此看来 化合物 46 的 Donor 基团的最大吸收与 Acceptor 的发射 有较大程度的重合，符合 FRET 机理的设计要求实验表 明该类主体对 $\mathrm{Hg}^{2+}$ 有选择性识别能力, 其中化合物 45 在加入 $\mathrm{Hg}^{2+}$ 后 $525 \mathrm{~nm}$ 吸收大幅度增强, 46 在 $575 \mathrm{~nm}$ 吸 收增强. 作者主要以 46 为例研究了光谱性能, 加入 $\mathrm{Hg}^{2}$ +使主体在 $450 \mathrm{~nm}$ (萠的苂光发射)处的苂光发射峰降低, $590 \mathrm{~nm}$ (罗丹明的苂光发射)处的发射大幅增强, Job 曲线 表明化合物 46 与 $\mathrm{Hg}^{2+}$ 按 $1: 1$ 的比例结合, 该 $\mathrm{Hg}^{2+}$ 识<smiles>CCN(CC)C1=CC2Oc3cc(N(CC)CC)ccc3C3(c4ccccc4C(=O)N3/N=C/c3ccc4ccc5cccc6ccc3c4c56)C2C=C1</smiles><smiles>CCN(CC)C1=CC2Oc3cc(N(CC)CC)ccc3C3(C(=S)c4ccccc43)N(/N=C/c3ccc4ccc5cccc6ccc3c4c56)C=CC2O1</smiles>

Chart 22 
别具有选择性强抗干扰能力强等优点. 通过 $\mathrm{Hg}^{2+}$ 加入 导致罗丹明开环，使得 FRET 过程畅通，从而实现了由 短波长激发到长波长发射这一过程.

2013 年 $\mathrm{Wu}$ 课题组 ${ }^{[39]}$ 根据 FRET 机理, 以 8-氨基喹 啉作为能量给体, 以罗丹明基团作为能量受体, 设计合 成了荧光传感分子 47 , 该主体化合物可以和 $\mathrm{Zn}^{2+}$ 配位, 由 $\mathrm{CHEF}$ 过程使其在 $500 \mathrm{~nm}$ 发射出绿色荧光, 而加入 $\mathrm{Hg}^{2+}$ 可以使罗丹明开环, 在 $562 \mathrm{~nm}$ 发射出红色荧光, 对 $\mathrm{Hg}^{2+}$ 的最低检测线可达 $1.05 \times 10^{-7} \mathrm{~mol} \cdot \mathrm{L}^{-1}$. 若在主 体 $+\mathrm{Zn}^{2+}$ 的体系中加入 $\mathrm{Hg}^{2+}$, 罗丹明开环在 $560 \mathrm{~nm}$ 出 现新的吸收峰, 其颜色由无色变为紫红色, 苂光光谱表 现为 $500 \mathrm{~nm}$ 的短波长发射降低, $562 \mathrm{~nm}$ 的长波长发射 增强, 苂光颜色为红色, 该识别过程对 $\mathrm{Hg}^{2+}$ 的最低检测 线可低达 $2.95 \times 10^{-8} \mathrm{~mol} \cdot \mathrm{L}^{-1}$, 该识别过程的灵敏度远 远高于主体直接与 $\mathrm{Hg}^{2+}$ 作用过程(Scheme 1).

2011 年 Duan 等 ${ }^{[40]}$ 报道了以香豆素酰胺衍生物作为 能量给体, 以罗丹明的葡萄糖衍生物作为能量受体的双
组份的 FRET 型阳离子识别受体 48 (Scheme 2). 单独的 香豆素酰胺衍生物的识别性能表现为 $\mathrm{Fe}^{3+}$ 和 $\mathrm{Cu}^{2+}$ 可以 使其在 $525 \mathrm{~nm}$ 处的苂光发射猝灭; 单独的罗丹明葡萄 糖亚胺在 $550 \mathrm{~nm}$ 有很弱的荧光发射峰, $\mathrm{Hg}^{2+}$ 和 $\mathrm{Cr}^{3+}$ 可以 使其 $550 \mathrm{~nm}$ 荧光增强，从上述实验现象可以看出，单独 的豆素酰胺衍生物和单独的罗丹明葡萄糖亚胺均表现 出不理想的识别性能(选择性低且效果不明显). 然而, 当作者将两种化合物混合后可以在纯水的缓冲溶液中 单一选择性识别 $\mathrm{Cr}^{3+}$, 而且抗干扰能力强, 其识别过程 具体表现为, 加入 $\mathrm{Cr}^{3+}$ 使其在 $423 \mathrm{~nm}$ (香豆素基团的吸 收)的吸收降低, $525 \mathrm{~nm}$ (开环罗丹明的吸收)增加, 溶液 颜色由淡黄色变为粉红色; 苂光光谱表现为 $475 \mathrm{~nm}$ (香 豆素基团的荧光发射)的短波长发射降低 $554 \mathrm{~nm}$ (开环 罗丹明的荧光发射)的长波长发射增强荧光颜色由淡蓝 色变为亮黄色，该过程的发生是由于 $\mathrm{Cr}^{3+}$ 的加入使香豆 素基团和罗丹明基团之间发生了荧光共振能量转移，即 能量由香豆素给体转移到罗丹明受体.
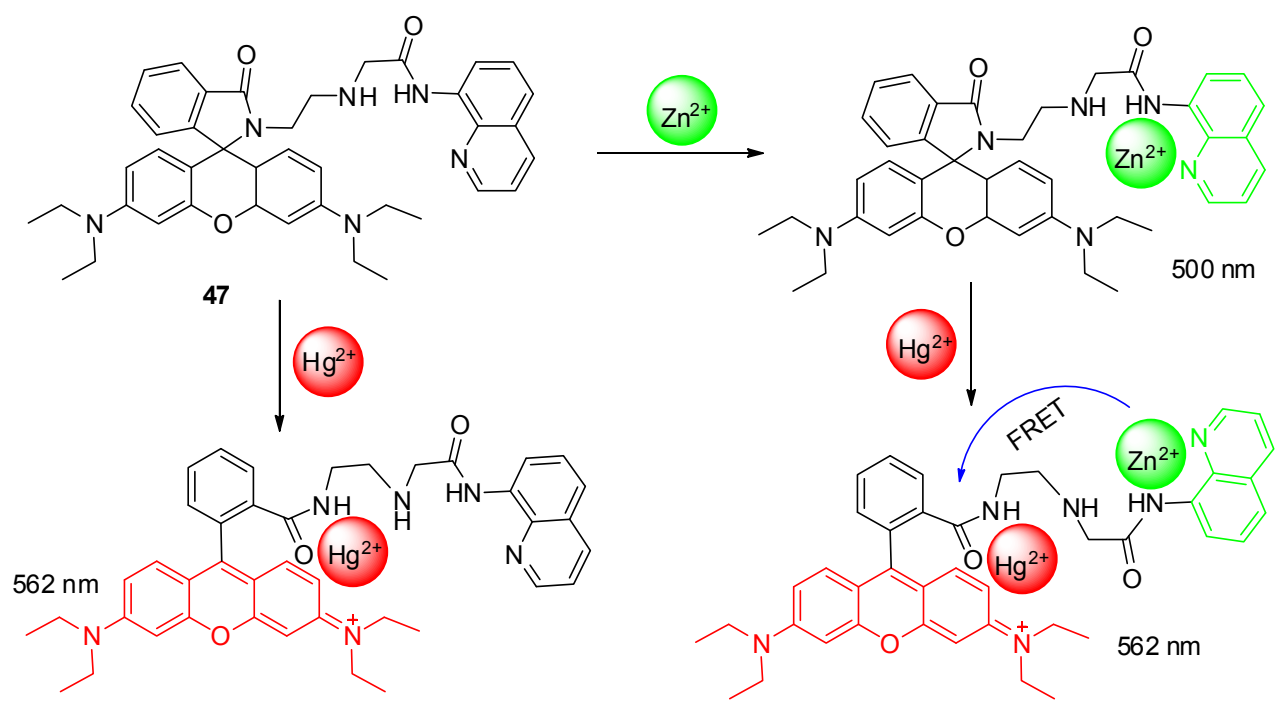

Scheme 1

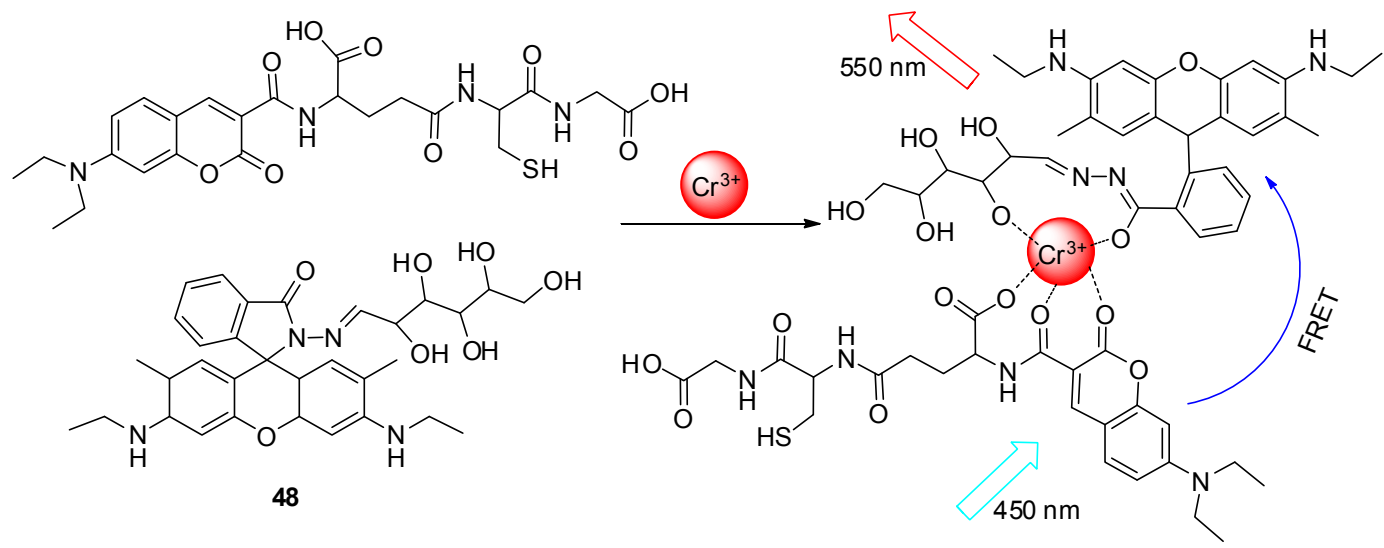

Scheme 2 
2013 年 Fedorova 等 ${ }^{[41]}$ 以苯并 15 冠 5 为离子结合位 点, 设计合成了基于 FRET 机理的一系列荧光传感分子 49 52 (Chart 23), 实验表明该系列化合物均对 $\mathrm{Mg}^{2+}$ 有 荧光响应, 我们以化合物 $\mathbf{5 2}$ 为例, 简要阐述其 $\mathrm{Mg}^{2+}$ 识 别光谱性能, 化合物 $\mathbf{5 0}$ 在 $410 \mathrm{~nm}$ 处有最大吸收, 加入 $\mathrm{Mg}^{2+}$ 后, 由于 $\mathrm{Mg}^{2+}$ 与冠醚氧原子配位, 减弱了供电子 能力导致其最大吸收峰蓝移至 $390 \mathrm{~nm}$, 苂光光谱则表 现为当加入 1 倍量 $\mathrm{Mg}^{2+}$ 时, 由于苂光共振能量转移作 用在 $590 \mathrm{~nm}$ 处出现一个新的苂光发射峰, 当加入 1 倍量 $\mathrm{Mg}^{2+}$ 时, $\mathrm{Mg}^{2+}$ 与两个冠醚络合, 阻止了分子内苂光共振 能量转移, 其苂光发射峰蓝移至 $490 \mathrm{~nm}$, 核磁滴定和二 维核磁谱图证实了 $\mathrm{Mg}^{2+}$ 与冠醚配位比例以及对应的识 别模式.

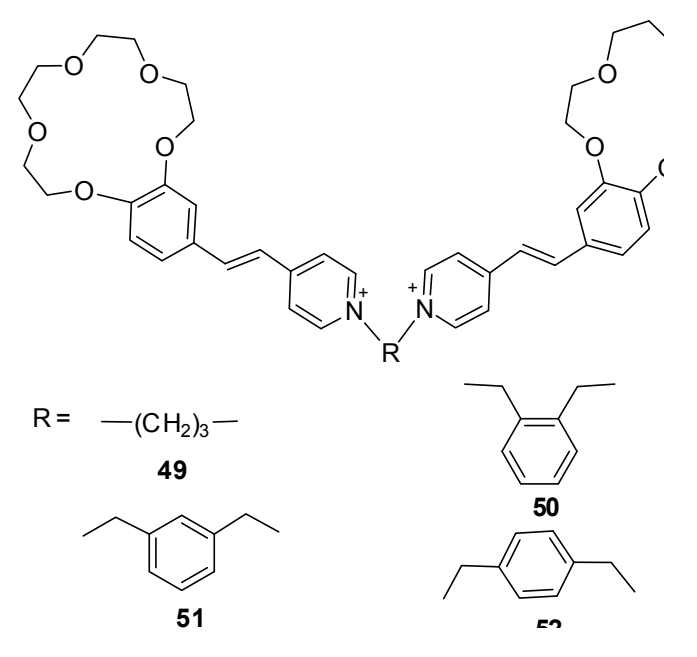

Chart 23
2010 年 $\mathrm{Wu}$ 等 ${ }^{[42]}$ 设计合成了一种基于 FRET 机理的 $\mathrm{Hg}^{2+}$ 比色传感器受体 53. 在该化合物的溶液中加入 $\mathrm{Hg}^{2+}$ 时, 该传感器分子颜色由为黄色变为粉红色, 从 UV-vis 吸收光谱中显示在 $560 \mathrm{~nm}$ 处出现一个新的吸收 峰. 将该溶液在 $365 \mathrm{~nm}$ 紫外灯照射下, 溶液颜色只有加 入 $\mathrm{Hg}^{2+}$ 的颜色由绿色荧光变为红色荧光, 而且其它阳 离子对其没有干扰，从而达到对 $\mathrm{Hg}^{2+}$ 的单一选择性双 通道识别(Scheme 3).

2012 年 $\operatorname{Lin}$ 等 ${ }^{[43]}$ 基于 FRET 荧光传感机理设计合成 了一种以罗丹明 $\mathrm{B}$ 为基本骨架的 $\mathrm{Cu}^{2+}$ 苂光开关化合物 54, 该化合物以罗丹明 $\mathrm{B}$ 和香豆素基团为荧光发色团, 以酰胺键位识别位点(Eq. 5). 作者发现, 在 $\mathrm{CH}_{3} \mathrm{CN} / \mathrm{H}_{2} \mathrm{O}$ $(V: V=2: 8)$, 控制缓冲体系的 $\mathrm{pH}=7.0$, 该受体分子 对 $\mathrm{Cu}^{2+}$ 有着很好的荧光选择性识别和高的灵敏度. 当 用 $410 \mathrm{~nm}$ 的最大激发波长去激发该受体分子，该受体 分子呈现蓝色的苂光, 但当加入 $\mathrm{Cu}^{2+}$ 之后, 溶液的荧光 变成红色, 随着 $\mathrm{Cu}^{2+}$ 的逐渐加入, 原本 $473 \mathrm{~nm}$ 处的峰 逐渐降低, 而在 $581 \mathrm{~nm}$ 处出现了一个新的宽峰. 作者还 对受体分子进行了生物细胞染色试验，当向 HeLa 细胞 中加入该受体分子的溶液时, 如果在荧光显微镜下面观 察到细胞的苂光由蓝色变为红色, 则可以说明此细胞中 有一定量的的 $\mathrm{Cu}^{2+}$ 的富集.

\section{4 激发态分子内质子转移}

激发态分子内质子转移(Excited-State Intramolecular Proton Transfer, ESIPT)是指当传感分子受光激发

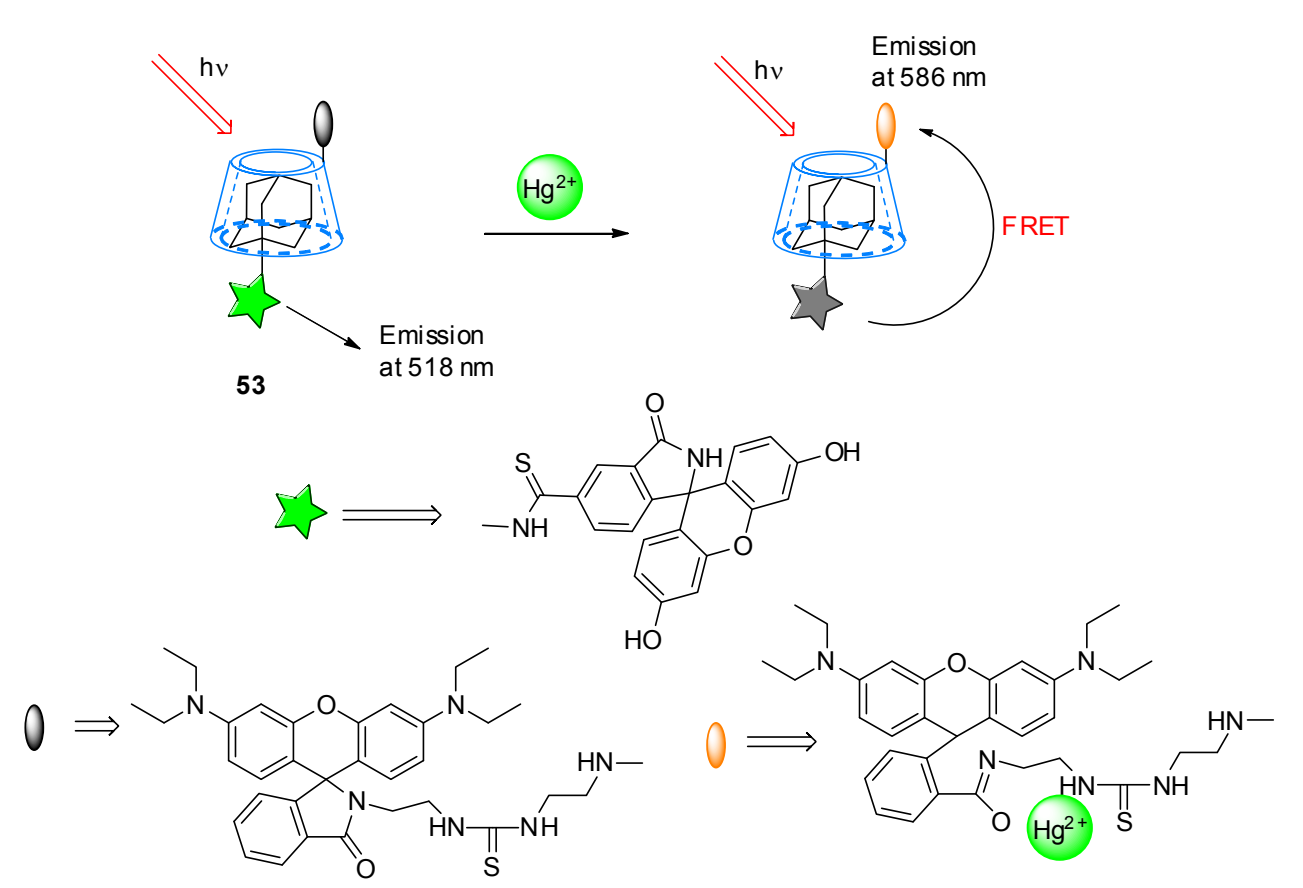

Scheme 3 


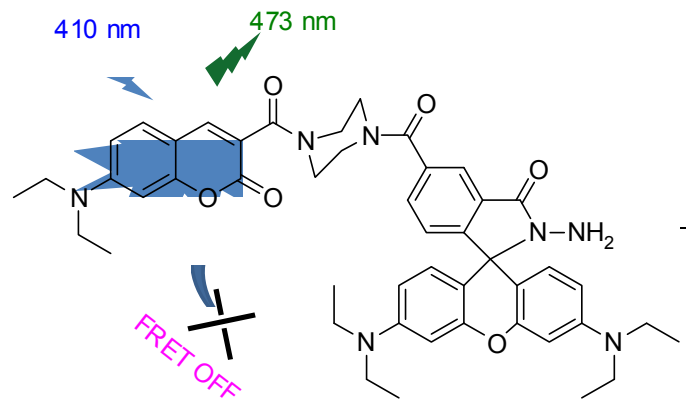

54

后, 发生在激发态分子内部邻近的质子给体与质子受体 之间的质子转移过程, ESIPT 效应广泛存在于自然界, 是生物过程中基本的质子转移方式之一. ESIPT 机理由 于其环境体系中具有独特的和显著的光谱特性而被应 用于光化学传感器的设计.

\subsection{ESIPT 型传感器的识别机理}

通常 ESIPT 型传感器的识别过程包括一个激发态 的质子从质子给体(一般为羟基或氨基)快速转移到质子 受体(一般为氧原子或氮原子), 该过程是以分子内氢键 来完成的, 所以在质子性溶剂中的 ESIPT 的过程易受溶 质-溶剂分子间氢键影响. ESIPT 型传感器的一个典型例 子如图 4 所示, ESIPT 过程可以有效地降低激发态分子 的光反应可能性并且显著地增强分子的耐光性，同时我 们可以观察到一个很明显的 Stokes 位移. ESIPT 过程中 将短波荧光归结为正常激发态所产生的苂光, 而将长波 发射确定为 ESIPT 反应所产生的互变异构体苂光. 因 此, ESIPT 过程很适合应用于设计根据特殊位移选择性 识别客体离子的光化学传感器.

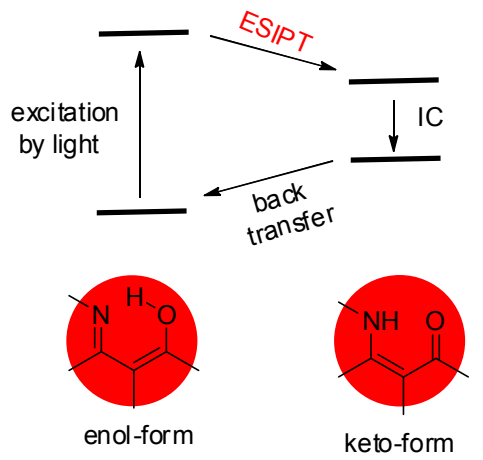

图 4 基于 ESIPT 过程的离子识别机理

Figure 4 Ion recognition mechanism based on ESIPT progress

\section{2 基于 ESIPT 过程的离子识别研究}

2011 年 Ahn 等 ${ }^{[44]}$ 按照 ESIPT 机理设计合成了 $\mathrm{Hg}^{2+}$ 识别受体化合物 $\mathbf{5 5}$, 其具体识别过程是在 $99 \%$ 水 的缓冲体系 $\mathrm{pH}=7.4$ 的主体溶液中加入 $\mathrm{Hg}^{2+}$ 导致烯醚 键断裂生成苯酚, 酚式结构在受到光照时转变为酮式,

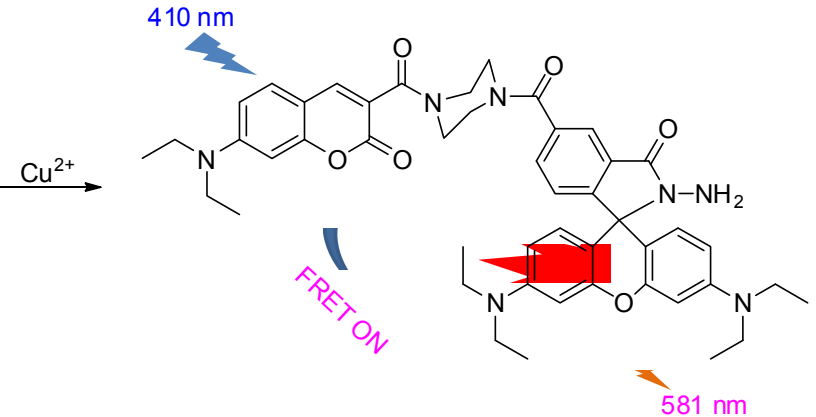

(5)

最大吸收峰由 $295 \mathrm{~nm}$ 红移至 $330 \mathrm{~nm}$, 荧光发射峰由 409 $\mathrm{nm}$ 红移至 $500 \mathrm{~nm}$, 苂光颜色由淡蓝色到亮绿色, 该识 别过程实现了对 $\mathrm{Hg}^{2+}$ 的单一性检测, 其结合比例为 2： 1, 反应生成了 $\mathrm{R}_{2} \mathrm{Hg}^{2+}$ (Scheme 4).

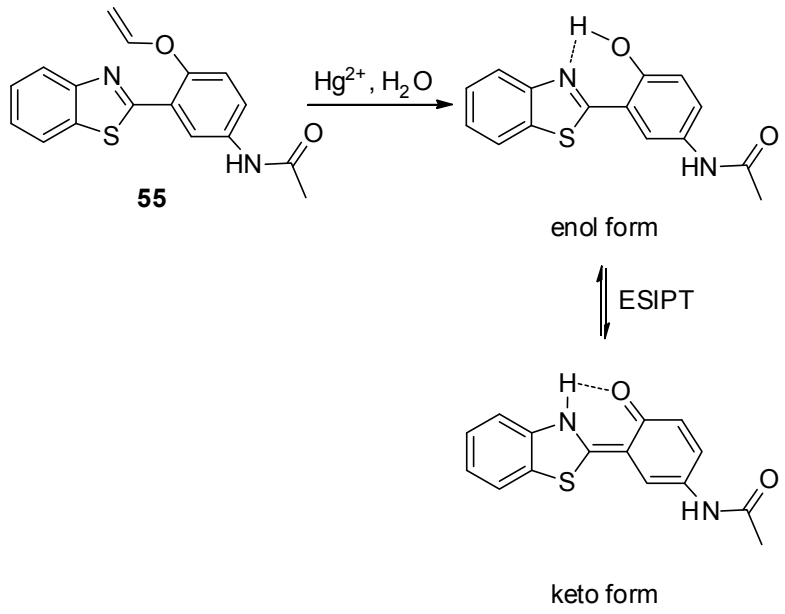

Scheme 4

2014 年 Chellappa 课题组 ${ }^{[45]}$ 设计合成了 ESIPT 型离 子识别受体 56 (Scheme 5), 该化合物在 $80 \%$ 的含水体系 中可以选择性紫外-荧光双通道识别 $\mathrm{Zn}^{2+}$, 而且抗干扰 能力强. 具体识别过程为 $\mathrm{Zn}^{2+}$ 加入使其醇式结构转化<smiles>O=C1C=Cc2ccccc2C1=CNn1c(-c2ccccc2)n[nH]c1=S</smiles>

56<smiles>CC(=S)N(NC=C1C(=O)C=Cc2ccccc21)c1ccccc1</smiles>

Scheme 5 
为酮式结构, 导致其最大吸收光谱从 $365 \mathrm{~nm}$ 红移到 430 $\mathrm{nm}, 410 \mathrm{~nm}$ 出的醇式荧光猝灭, $548 \mathrm{~nm}$ 的酮式苂光增 强，作者应用 DPT 计算进一步证实了该识别过程.

2013 年 Goswami 等 ${ }^{[46]}$ 设计合成了 ESIPT 型离子识 别受体 57 和 58, 在甲醇和水混合溶液 $\left(\mathrm{CH}_{3} \mathrm{CN} / \mathrm{H}_{2} \mathrm{O}, V\right.$ : $V=1: 1, \mathrm{pH}$ 7.2)中, $\mathrm{Zn}^{2+}$ 的加入可以使其转化为酮式结 构并与 $\mathrm{Zn}^{2+}$ 配位, 导致其吸收光谱红移, 长波长苂光增 强, 实现对 $\mathrm{Zn}^{2+}$ 的紫外-荧光双通道检测(Scheme 6).<smiles></smiles><smiles>CCN(CC)c1ccc(/C=N\c2ccccc2)c(OC)c1</smiles>

58

\section{Scheme 6}

2012 年 Kim 等 ${ }^{[47]}$ 按照 ESIPT 荧光传感机理设计合 成了钳形离子识别受体 $\mathbf{5 9}$ (Chart 24 ), 在 $\mathrm{DMSO} / \mathrm{CH}_{3} \mathrm{CN}$ $(V: V=1: 9)$ 混合溶剂中表现出对 $\mathrm{Zn}^{2+}$ 的单一性识别, $\mathrm{Zn}^{2+}$ 与主体分子按照 $1: 1$ 的比例配位, 该配位作用可 以使醇式结构转化为酮式结构, 形成夹心的配合物, 从 而使其在 $448 \mathrm{~nm}$ 处的苂光猝灭, $390 \mathrm{~nm}$ 出现新的荧光 峰, 作者通过 DFT 理论计算证实了该识别机理.

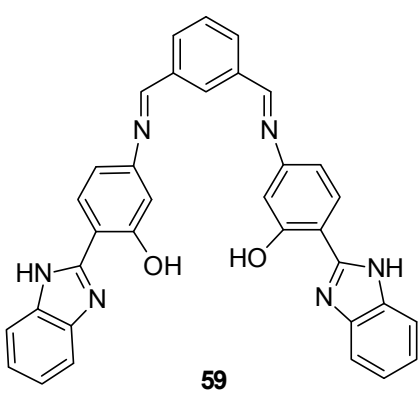

Chart 24

同年 $\mathrm{Kim}$ 课题组 ${ }^{[48]}$ 设计合成了含菜酚结构的受体 分子 60 , 实验表明 $\mathrm{Zn}^{2+}$ 加入可以其发生 ESIPT 过程, 而 导致主体在 424 和 $328 \mathrm{~nm}$ 的吸收峰增强, $420 \mathrm{~nm}$ 醇式结 构的荧光峰降低, $565 \mathrm{~nm}$ 的酮式苂光峰增强 51 倍, 荧光 颜色从蓝变为亮黄色, Job 曲线在 0.5 处有顶点, 说明其 结合比例为 $1: 1$, EDTA 的加入可以使吸收光谱和荧光 光谱恢复到主体状态，说明该过程是配位而非金属催化 的反应(Eq. 6).

2011 年 Pang 等 ${ }^{[49]}$ 以 2-邻羟基苯基苯并噁唑为荧光 信号基团, 以 $\mathrm{N}$ 烷基吡啶和 $\mathrm{Zn}^{2+}$ 的配合物为阴离子识别 位点，设计合成了 ESIPT 型荧光传感分子 61, 该主体本 身是 ESIPT 屏蔽的, 加入阴离子之后只有焦磷酸根可以 使其 ESIPT 打开, $425 \mathrm{~nm}$ 的短波长苂光猝灭, 在 $518 \mathrm{~nm}$ 出现一个新的荧光峰, 苂光颜色由淡蓝色变为亮绿色. 由于 ATP 具有和焦磷酸根相似的结构, 该识别主体可 以用于检测识别生物体中的 ATP 分子的存在(Eq. 7).

2014 年, 本课题组 ${ }^{[50]}$ 以酚嗪基团作为荧光信号基 团, 以咪唑和 $\mathrm{OH}$ 作为离子结合位点, 设计合成了 ESIPT 型的 $\mathrm{Fe}^{3+}$ 苂光传感分子 $\mathbf{6 2}$, 在 DMSO 溶液中, 主 体分子在 $533 \mathrm{~nm}$ 处有很强的荧光发射峰, 为醇式结构 的发射峰, 加入 $\mathrm{Fe}^{3+}$ 后, 由于 $\mathrm{Fe}^{3+}$ 的配位作用导致醇式 结构转变为酮式结构, $533 \mathrm{~nm}$ 的苂光峰明显减弱, 该传 感分子实现了对 $\mathrm{Fe}^{3+}$ 检测, 其最低检测线达 $4.8 \times 10^{-6}$ $\mathrm{mol} \cdot \mathrm{L}^{-1}$ (Eq. 8).

2012 年 You 课题组 ${ }^{[51]}$ 设计合成了含菜酚结构的受 体分子 63 (Chart 25), 实验表明 $\mathrm{Zn}^{2+}$ 加入可以其发生 ESIPT 过程, 而导致主体在 $495 \mathrm{~nm}$ 的吸收峰增强, 550 $\mathrm{nm}$ 的酮式荧光峰增强, 苂光颜色从蓝变为亮黄色, Job 曲线在 0.5 处有顶点, 说明其结合比例为 $1: 1$, EDTA 的 加入可以使吸收光谱和荧光光谱恢复到主体状态, 实现 了 “OFF-ON-OFF” 型荧光开关过程.<smiles>Oc1cc2ccccc2cc1-c1nc(-c2ccccn2)cs1</smiles>
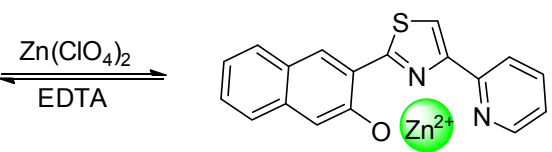


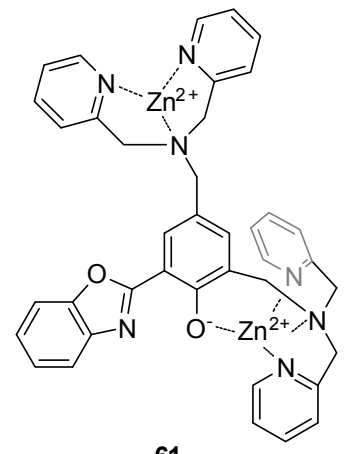

61

ESIPT masked
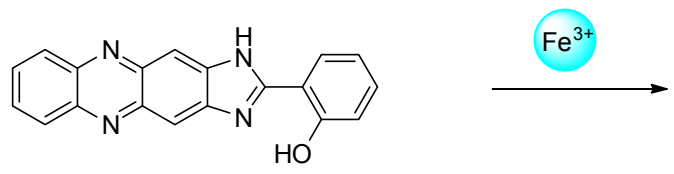

62

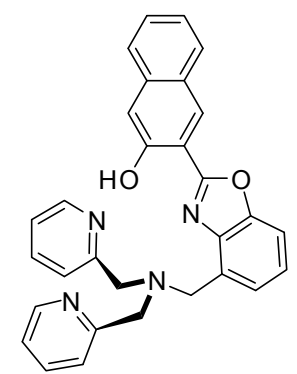

63

Chart 25

\section{5 激基缔合物生成/消失}

激基缔合物(Monomer-Excimer)是指一个苂光基团 在激发态与另一个苂光团接近, 此时可以观察到双重荧 光, 位于短波长的荧光为单体荧光, 长波长的荧光为激 基缔合物产生的荧光. 激基缔合物的形成主要受单体浓 度和溶剂粘度的影响, 单体浓度较低时, 通常观察到单 体荧光; 单体浓度足够大, 环境利于两个荧光团接近, 且激发单体寿命较长时, 容易形成激基缔合物.

\subsection{Monomer-Excimer 型传感器的识别机理}

Monomer-Excimer 型荧光传感器的识别机理如图 5 所示, 如果识别受体含有两个相同的荧光团, 与客体离 子的结合可以导致两荧光团距离发生变化, 促进了激基 缔合物的形成或者破坏单体本身的激基缔合物结构, 导 致激基缔合物荧光的产生或者消失, 从而达到对客体离 子的识别. 具有大平面的化合物, 如含有萗、葱、芘等, 较易通过 $\pi-\pi$ 堆积作用形成激基缔合物, 因而被广泛应

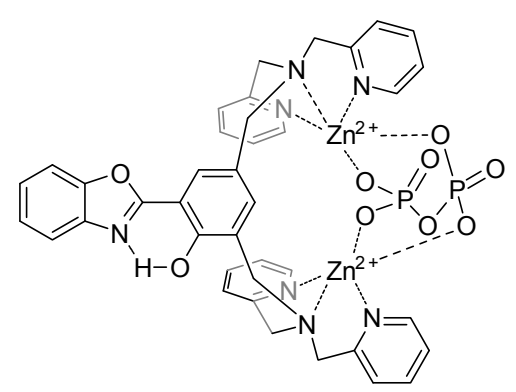

ESIPT turned on

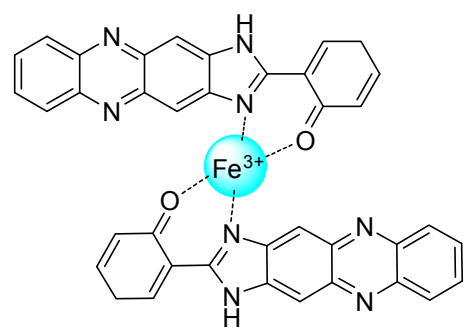

(8)

用于激发态单体与激基缔合物共存的荧光传感分子的 设计.

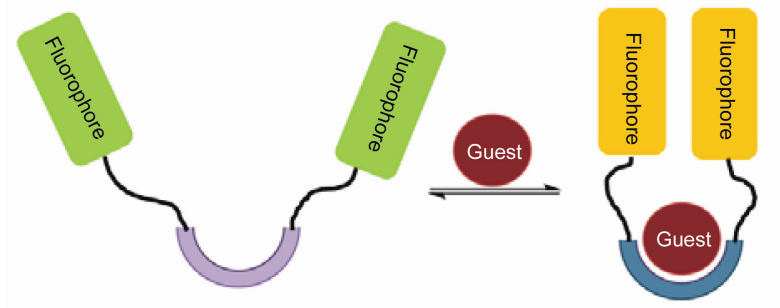

图 5 基于 Monomer-Excimer 过程的离子识别机理

Figure 5 Ion recognition based on monomer-excimer progress

\section{2 基于 Monomer-Excimer 的离子识别研究}

2012 年 Debasis 等 ${ }^{[52]}$ 依照激基缔合的苂光传感机 理设计合成了离子识别受体化合物 64 (Chart 26), 该化 合物在 DMSO 和水的混合体系 $(V: V=1: 1)$ 中, 和 $\mathrm{Ni}^{2+}$ 配位形成激基缔合物, 加 $\mathrm{Ni}^{2+}$ 之后在 $345 \mathrm{~nm}$ 的单体 荧光发射峰降低, $430 \mathrm{~nm}$ 处形成的缔合物苂光发射峰增 强，化合物 64 对 $\mathrm{Ni}^{2+}$ 的最低检测线可达 $\times 10^{-6} \mathrm{~mol} \cdot \mathrm{L}^{-1}$.

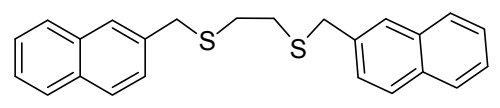

64

\section{Chart 26}

2011 年 Lee 课题组 ${ }^{[53]}$ 以萠为苂光信号基团, 以氨 基酸基团为结合位点，设计合成了 $\mathrm{Hg}^{2+}$ 传感分子 65 , 在 含水 $98 \%$ 的 DMF 溶液中主体化合物的荧光发射在 400 $\mathrm{nm}$ 处, 加入 $\mathrm{Hg}^{2+}$ 之后, $\mathrm{Hg}^{2+}$ 与 $\mathrm{S}$ 原子和 $\mathrm{N}$ 原子配位形 
成缔合体系，从而使其在 $480 \mathrm{~nm}$ 处出现缔合态的苂光， 荧光颜色由蓝色变为绿色, 主体与 $\mathrm{Hg}^{2+}$ 结合的稳定常 数为 $7.84 \times 10^{12} \mathrm{~L}^{2} \cdot \mathrm{mol}^{-2}$ (Eq. 9).

2010 年 Yao 等 ${ }^{[54]}$ 同样以萠为荧光信号基团, 合成 了双席夫碱离子识别受体化合物 66, 主体化合物在 238, 283 和 $326 \mathrm{~nm}$ 有萠环的特征吸收, 并在 $395 \mathrm{~nm}$ 有一个 较弱的亚胺键的共轭吸收, 当向主体中加入 $\mathrm{Hg}^{2+}$ 后, 在 $350 \sim 520 \mathrm{~nm}$ 出现一个宽的吸收峰, 这是由于 $\mathrm{Hg}^{2+}$ 和 $\mathrm{N}$ 原子配位导致的分子内电荷转移造成的, 该配合物的单 体发射在 $410 \mathrm{~nm}$ 而在 $462 \mathrm{~nm}$ 出现很强的缔合态一个峰, 化合物 66 对 $\mathrm{Hg}^{2+}$ 识别的检测线可低达 $2 \times 10^{-7} \mathrm{~L}$ ・ $\mathrm{mol}^{-1}$ (Eq. 10).

2011 年 Yoon 课题组 ${ }^{[5]}$ 同样以萠为荧光信号基团, 以吡定和 $\mathrm{N}$ 原子为结合位点设计合成了离子识别受体 化合物 67, DMSO-HEPES (pH 7.4, $V: V=1: 1$ ) 溶液中 在 $463 \mathrm{~nm}$ 有荧光发射峰, 该荧光为萠环经 $\pi-\pi$ 堆积后形 成的缔合物的发射, 加入 1 倍 $\mathrm{Ag}^{+}$之后, 分子内的 $\pi-\pi$ 堆积作用消失, 在 $399 \mathrm{~nm}$ 处出现分子间堆积作用的荧 光峰, 该 $\mathrm{Ag}^{+}$识别过程的结合常数 $K_{\mathrm{a}}=3.2 \times 10^{5} \mathrm{~L}$ $\mathrm{mol}^{-1}$ (Eq. 11).

Lin 等 ${ }^{[56]}$ 依照激基缔合的苂光传感机理设计合成了 离子识别受体化合物 68 (Chart 27), 该化合物对 $\mathrm{Al}^{3+}$ 有
选择性识别性能, 和 $\mathrm{Al}^{3+}$ 配位形成激基缔合物, 加 $\mathrm{Al}^{3+}$ 之后 $327 \mathrm{~nm}$ 吸收光谱有小幅度 $(7 \mathrm{~nm})$ 的红移, 由于配位 阻碍了 PET 过程, 使得 $395 \mathrm{~nm}$ 的单体荧光发射峰增强 15 倍, $500 \mathrm{~nm}$ 处形成的缔合物荧光发射峰增强 56.8 倍, 发射出亮黄色的菼光.<smiles>CCCCOc1ccc2cc(CNCCNCc3cc4ccc(OC(C)(C)C)cc4oc3=O)c(=O)oc2c1</smiles>

Chart 27

\section{6 螯合作用导致荧光增强}

螯合作用导致荧光增强(Chelation-Enhanced Fluorescence, $\mathrm{CHEF}$ )主要是指与荧光团相连的 $\mathrm{N}, \mathrm{O}, \mathrm{S}$ 等杂 原子与金属离子络合，阻止主体分子的 PET 过程，从而 导致荧光团发出荧光, 达到对金属离子的识别过程.

\subsection{CHEF 型传感器的识别机理}

CHEF 型传感器的识别过程与 PET 型荧光探针相类 似, 由发色团(荧光团)、连接臂和受体三部分组成, 荧光 团大多是含有大共轭结构的体系, 例如萗、葱、萠等, 它
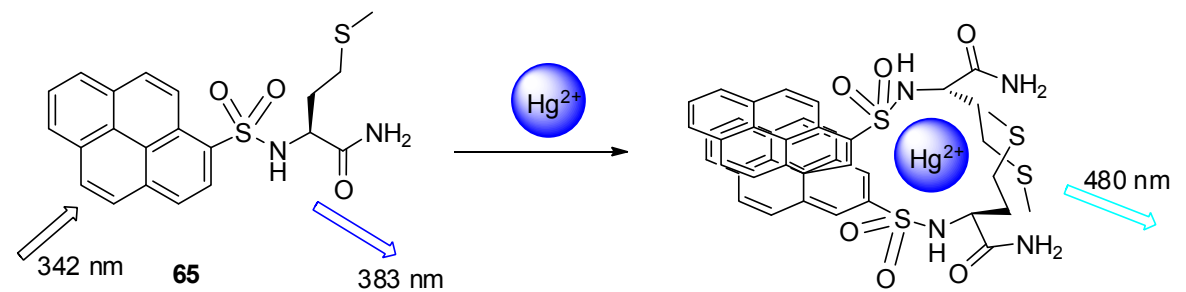

(9)
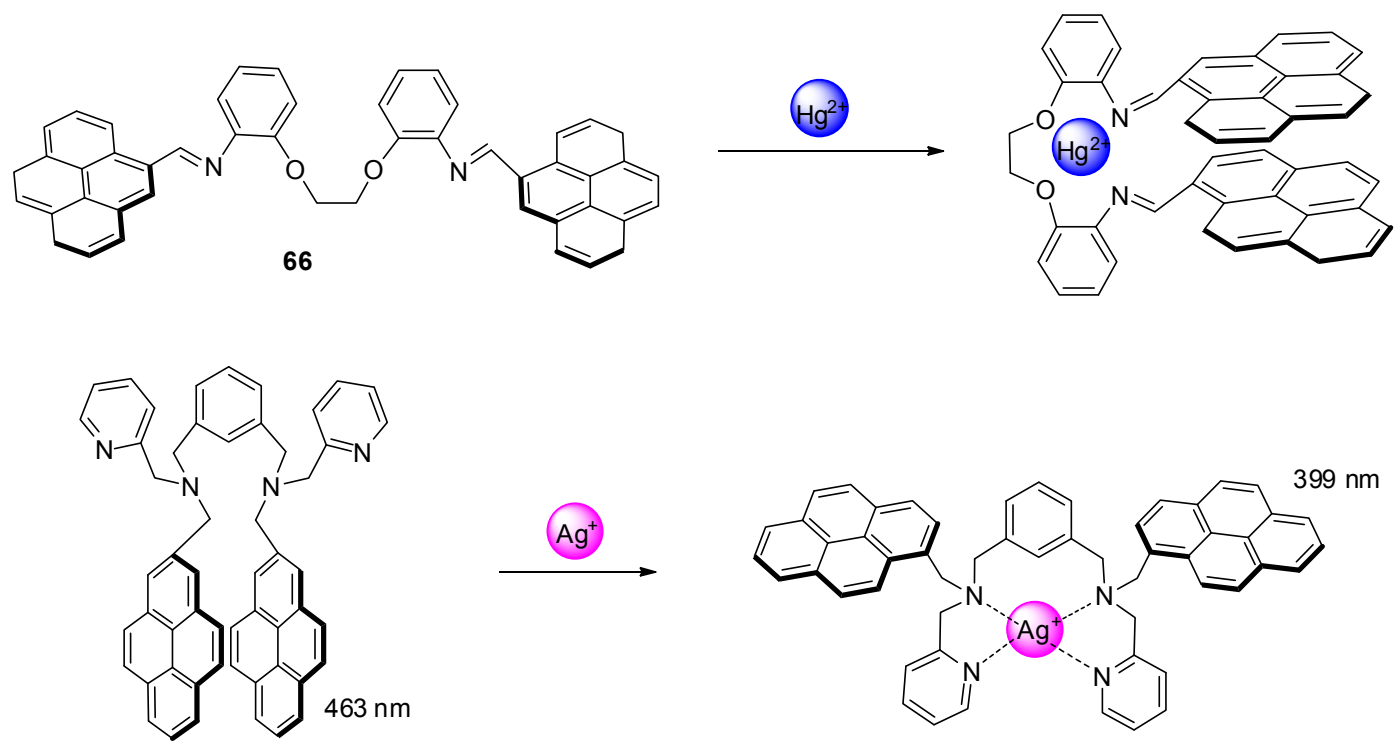

67
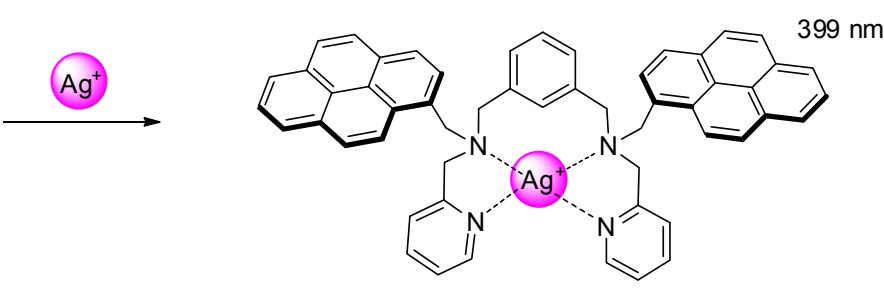
们是光能的吸收和荧光发射的场所. 识别功能单元则含 有 $\mathrm{N}, \mathrm{O}, \mathrm{S}$ 等杂原子, 可以很好地结合客体离子. $\mathrm{CHEF}$ 型苂光传感器与客体离子的结合过程如图 6 所示, 客体 离子与识别主体络合, 导致主体分子中与菼光团相连基 才的 HOMO 轨道电子与金属离子配位, 使荧光才被激 发的 LUMO 轨道电子可以顺利跃迁至 HOMO 轨道, 使 PET 过程受阻，荧光团的荧光得以恢复.

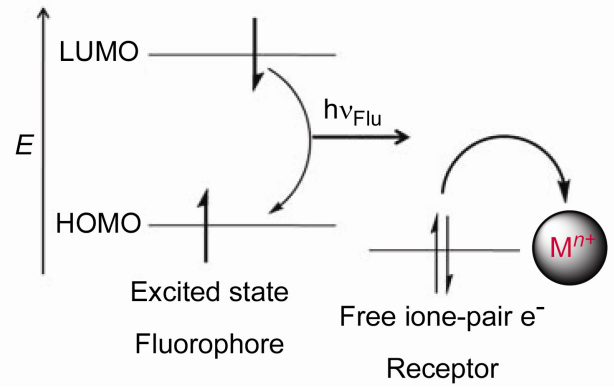

图 6 基于 $\mathrm{CHEF}$ 过程的离子识别机理

Figure 6 Ion recognition based on CHEF progress

\section{2 基于 CHEF 过程的离子识别研究}

2012 年 Zhang 等 ${ }^{[57]}$ 设计合成了一种 $\mathrm{Zn}^{2+}$ 荧光开关, 该化合物 69 (Chart 28)是含有吡啶基团的三足腙类化合 物. 作者研究发现, 该受体分子对 $\mathrm{Zn}^{2+}$ 有着很好的比色 选择性识别和高的灵敏度, 当加入 $\mathrm{Zn}^{2+}$ 时, 溶液的颜色 由无色变为黄色. 当用 $370 \mathrm{~nm}$ 的最大激发波长去激发 加入 $\mathrm{Zn}^{2+}$ 之后该受体分子, 溶液的苂光变成红色, 随着 $\mathrm{Zn}^{2+}$ 的逐渐加入, 在 $582 \mathrm{~nm}$ 处出现了一个新的宽峰.<smiles>O=C(/C=N/NC(N/N=C/c1ccccn1)N/N=C/c1ccccn1)Oc1ccccn1</smiles>

69

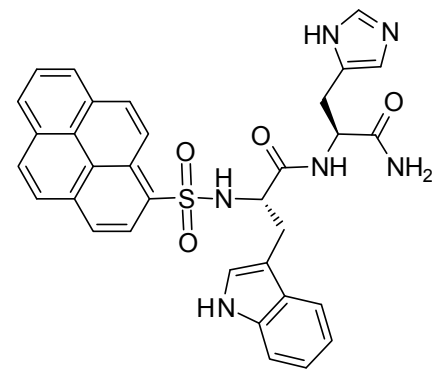

70

Chart 28

Jang 等 ${ }^{[58]}$ 以萠为苂光团设计合成了一种 $\mathrm{Ag}^{+}$苂光 传感器 70 (Chart 28), 由于该化合物含有磺酰基才的氨 基酸衍生物, 具有较好的水溶性, 实验表明该化合物实 现了 $100 \%$ 含水体系中对 $\mathrm{Ag}^{+}$的选择性识别, 它和 $\mathrm{Ag}^{+}$ 按照 $2: 1$ 的比例配位, 导致主体在 $400 \mathrm{~nm}$ 处的苂光峰 降低, $480 \mathrm{~nm}$ 处的苂光增强, 显示亮绿色苂光.

2013 年 Xie 等 ${ }^{[59]}$ 报道了一种 $\mathrm{Zn}^{2+}$ 菼光开关, 该化合 物 71 是含有吡咯基团苂光传感化合物. 作者研究发现,
该受体分子对 $\mathrm{Zn}^{2+}$ 有着很好的荧光选择性识别和高的 灵敏度，当加入 $\mathrm{Zn}^{2+}$ 时，化合物 71 与 $\mathrm{Zn}^{2+}$ 以 $2: 1$ 的比 例配位, 主体在 $450 \mathrm{~nm}$ 的吸收峰降低, $540 \mathrm{~nm}$ 吸收增 强, 在 $485 \mathrm{~nm}$ 有一个等吸收点, $575 \mathrm{~nm}$ 的荧光打开, 呈 现亮黄色荧光，实现了对 $\mathrm{Zn}^{2+}$ 的紫外-苂光双通道识别， 其最低检测线达 $4.4 \times 10^{-8} \mathrm{~mol} \cdot \mathrm{L}^{-1}$ (Eq. 12).
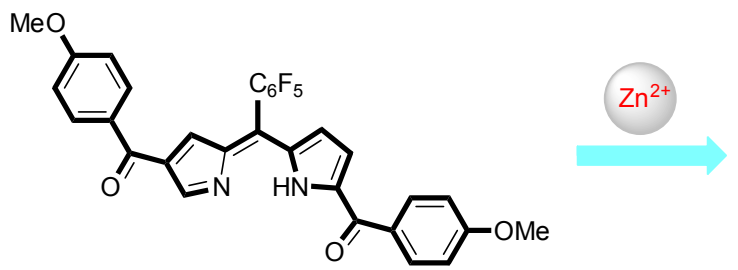

71

Weak fluorescence

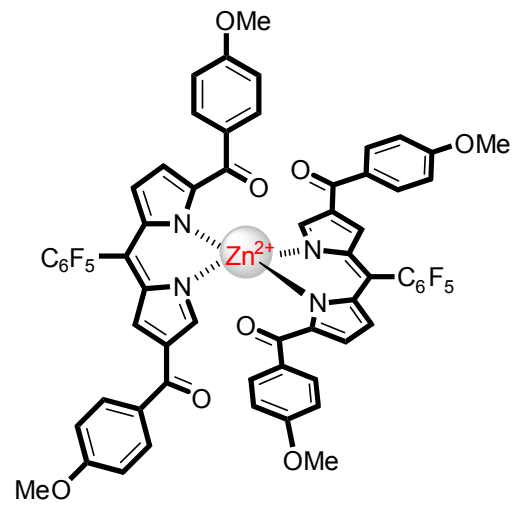

2012 年 Cheng 等 ${ }^{[60]}$ 设计合成了环状席夫碱类离子 识别受体 72 (Chart 29), 该化合物可以选择性识别 $\mathrm{Zn}^{2+}$, 与 $\mathrm{Zn}^{2+}$ 以 $1: 1$ 的比例结合, $\mathrm{Zn}^{2+}$ 加入使其在 $370 \mathrm{~nm}$ 的 联菜基团的荧光猝灭, $470 \mathrm{~nm}$ 处出现配合物的苂光发射 峰, 化合物 72 对 $\mathrm{Zn}^{2+}$ 识别的最低检测线为 $1.53 \times 10^{-5}$ $\mathrm{mol} \cdot \mathrm{L}^{-1}$ ，该识别过程不受其它共存离子的干扰.

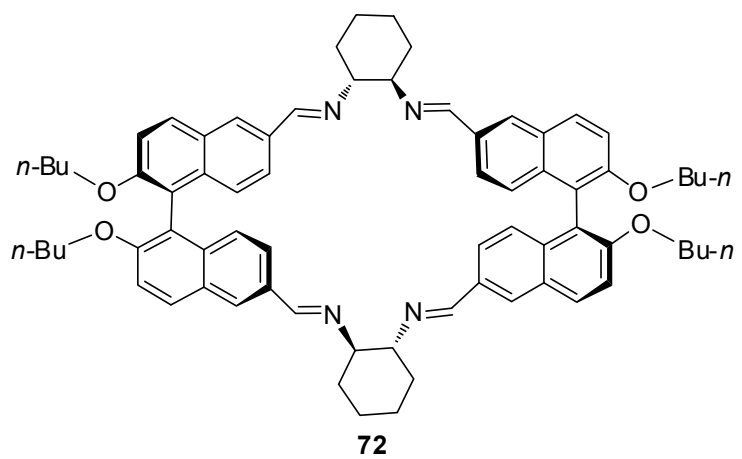

Chart 29

2013 年 Rosa 课题组 ${ }^{[61]}$ 设计合成了一种 D- $\pi$-A 型离 子识别受体 73, 该化合物具有很好的水溶性, 可以在 $100 \%$ 纯水相中实现对 $\mathrm{Hg}^{2+}$ 的选择性识别, Job 曲线在 
0.5 处有顶点, 说明该主体与 $\mathrm{Hg}^{2+}$ 以 $1: 1$ 比例结合, $\mathrm{Hg}^{2+}$ 的加入使其在 $365 \mathrm{~nm}$ 吸收降低, $450 \mathrm{~nm}$ 吸收峰增 强, 并且在 $455 \mathrm{~nm}$ 出现很强的荧光, 实现了纯水相中对 $\mathrm{Hg}^{2+}$ 的紫外荧光双通道检测(Eq. 13).

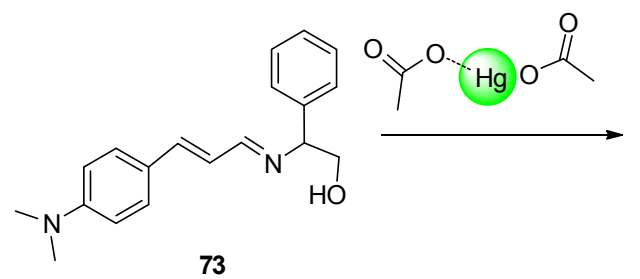<smiles>CC(=O)OC1CCCCC1/N=C/C=C/c1ccc(N(C)C)cc1</smiles>

2013 年, 魏太保等 ${ }^{[62]}$ 以萗环作为荧光信号基团, 以 吡啶和 $\mathrm{OH}$ 作为离子结合位点, 设计合成了 $\mathrm{CHEF}$ 型的 荧光传感分子 74, 在 DMSO 溶液中, 主体分子本身没有 苂光发射. 加入 $\mathrm{Zn}^{2+}$ 后, 由于 $\mathrm{Zn}^{2+}$ 和 $\mathrm{N}$ 原子的配位作用 阻碍光诱导的电子转移过程, 使得主体分子的荧光恢 复, 在 $490 \mathrm{~nm}$ 处发射出绿色荧光, 在主体和 $\mathrm{Zn}^{2+}$ 的体 系中加入 EDTA 可竞争脱去 $\mathrm{Zn}^{2+}$, 苂光再次猝灭, 该传 感分子以金属螯合的苂光增强原理实现了对 $\mathrm{Zn}^{2+}$ 的苂 光 “OFF-ON-OFF” 的循环响应, 达到了对 $\mathrm{Zn}^{2+}$ 的选择 性识别(Eq. 14).

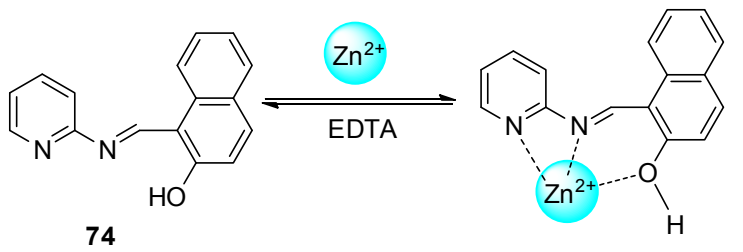

\section{7 其它荧光传感过程}

\section{1 通过化学键的能量转移}

通过化学键的能量转移 (Through Bond Energy Transfer, TBET)的例子传感设计理论上要求能量给体的 发射峰和能量受体的吸收峰有较大程度的重叠, 在 TBET 体系中能量接受体和能量供给体之间通过共轭的 连接臂相连, 从而阻止了受体和供体的共平面性和共轭 性, 其识别过程是用能量给体的吸收光谱来激发得到能 量受体的发射.

2011 年 Kumar 研究小组 ${ }^{[63]}$ 以菜二酰亚胺为能量给 体, 以罗丹明为能量受体, 苯作为连接臂合成了离子传 感分子 75, 在四氢呋喃和水的混合溶剂中主体在 363 $\mathrm{nm}$ 处有萗酰亚胺的吸收峰, 加 $\mathrm{Hg}^{2+}$ 之后 $363 \mathrm{~nm}$ 的吸收 峰增强, 并在 $565 \mathrm{~nm}$ 出现一个新的吸收峰, 说明 $\mathrm{Hg}^{2+}$ 导致罗丹明开环, 溶液颜色由无色变为粉红色, 主体表 现出非常弱的苂光, 加 $\mathrm{Hg}^{2+}$ 之后, 激发波长为 $360 \mathrm{~nm}$ 时, 在 $578 \mathrm{~nm}$ 处出现很强的黄色荧光, 该过程实现了 $\mathrm{Hg}^{2+}$ 诱发的 TBET 能量转移, 达到了对 $\mathrm{Hg}^{2+}$ 的选择性识 别(Eq. 15).

2013 年 Fan 等 ${ }^{[64]}$ 以同样的思路设计合成了一个 TBET 型 $\mathrm{Cu}^{2+}$ 苂光传感分子 76, 该化合物在 $431 \mathrm{~nm}$ 处 有萗酰亚胺的吸收峰, 加入 $\mathrm{Cu}^{2+}$ 之后在 $546 \mathrm{~nm}$ 处出现 罗丹明的吸收峰, 溶液颜色由黄绿色变为粉红色, 达到 了对 $\mathrm{Cu}^{2+}$ 的裸眼识别, 以 $420 \mathrm{~nm}$ 波长激发主体化合物 时, 在 $535 \mathrm{~nm}$ 有一个菜酰亚胺基团的苂光峰, 此时罗丹 明是合环的，说明单独的主体分子没有 TBET 过程，当 加入 $\mathrm{Cu}^{2+}$ 之后, $535 \mathrm{~nm}$ 的发射峰降低, $577 \mathrm{~nm}$ 处的发射 峰剧烈增强, 经计算其能量转移效率可达 $81.3 \%$, 该过 程对 $\mathrm{Cu}^{2+}$ 的最低检测线可达 $3.88 \times 10^{-7} \mathrm{~mol} \cdot \mathrm{L}^{-1}$, 实现 了对 $\mathrm{Cu}^{2+}$ 的高灵敏度的紫外-荧光双通道检测(Eq. 16).
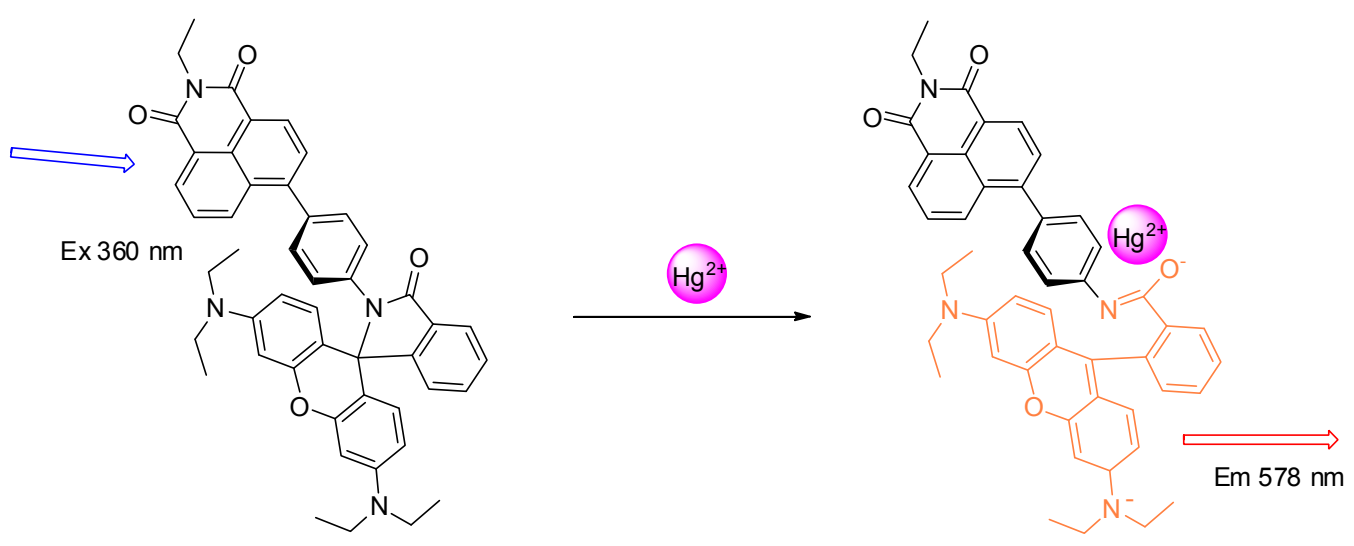

75 


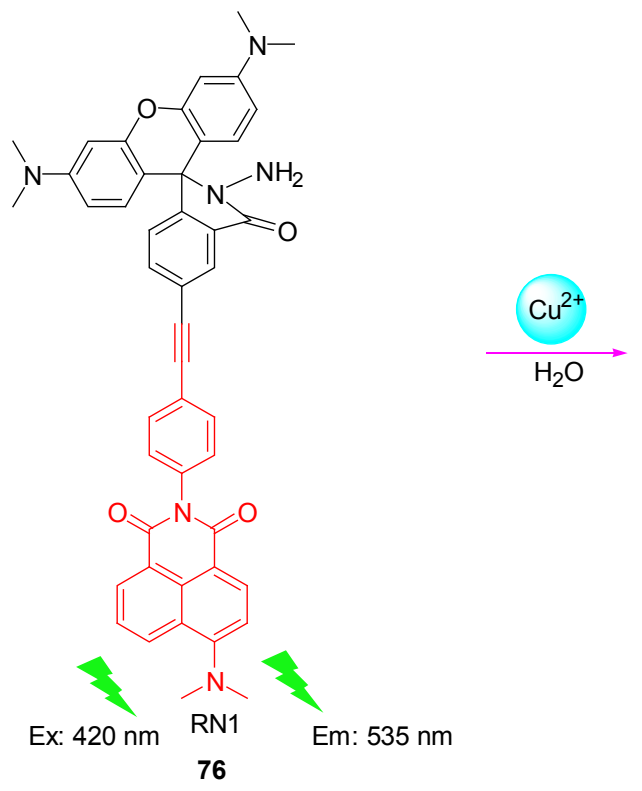

\section{2 反应型荧光传感}

该方法主要是利用特定的化学反应, 即被检测离子 与受体分子之间发生化学反应, 生成新的化合物, 从而 使菼光改变达到识别的目的, 比如利用 $\mathrm{CN}^{-}$的亲核性, 是其与受体发生亲核加成反应达到对 $\mathrm{CN}^{-}$的识别 ${ }^{[65 \sim 70]}$, 另一种情况是利用金属催化的化学反应，达到对金属离 子的识别 ${ }^{[71]}$. 该类方法的优越性是可以利用特定的反 应识别特定的离子, 大大提高识别的选择性.

2013 年, 魏太保等 ${ }^{[2]}$ 用氨基硫艮和 4-硝基苯基呋 喃甲醛设计合成了一种含苯基呋喃荧光团的缩氨基硫 艮受体分子 77. 采用 4-硝基苯基呋喃基团为信号报告 基团，可以使受体具备荧光响应的能力; 利用录的亲硫 性, 采用缩氨基硫䐂基团作为识别位点. 受体对 $\mathrm{Hg}^{2+}$ 有 着显著的荧光识别效果, $\mathrm{Hg}^{2+}$ 与缩氨基硫脲反应使其转 化为缩氨基脲, 缩氨基腿在分子间氢键作用的驱动下结 合成二聚体, 产生了很明显的 OFF-ON 型苂光信号响 应，受体化合物 $\mathbf{S}_{\mathbf{1 2}}$ 对 $\mathrm{Hg}^{2+}$ 的最低检测线为 $1.67 \times 10^{-6}$ $\mathrm{mol} \cdot \mathrm{L}^{-1}$ (Eq. 17).

2012 年 Lee 等 ${ }^{[73]}$ 设计合成了偶氮类离子识别受体 78, 在 $\mathrm{pH}=7$ 的水溶液中, 加入 $\mathrm{Cu}^{2+}$ 可以使主体的吸收

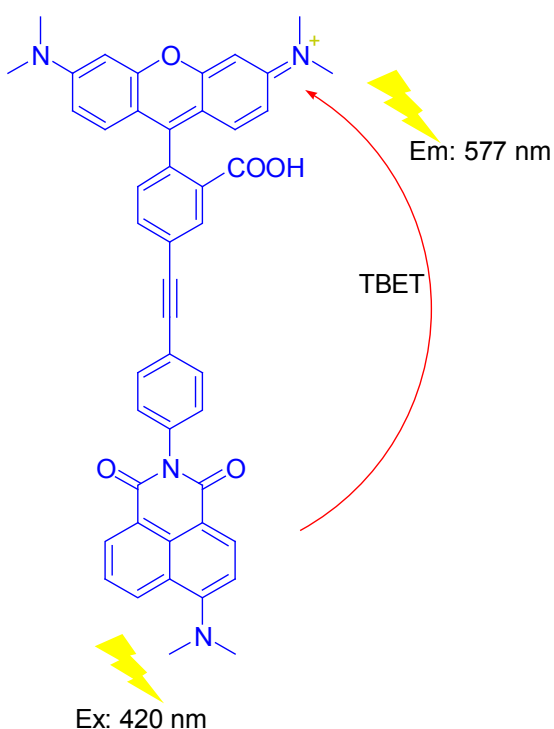

(16)

光谱 $480 \mathrm{~nm}$ 蓝移至 $375 \mathrm{~nm}$, 溶液颜色由黄色变为无色, $490 \mathrm{~nm}$ 处的苂光增强 80 多倍, 发射出亮绿色的苂光, 该过程利用 $\mathrm{Cu}^{2+}$ 催化的有机反应, 实现了对 $\mathrm{Cu}^{2+}$ 的紫 外-苂光双通道选择性识别(Scheme 7).

2010 年, 国内田禾等 ${ }^{[74]}$ 根据 $\mathrm{Hg}^{2+}$ 的亲硫性, 设计 合成了一系列硫腿类离子识别受体 79 81, 均可以达 到对 $\mathrm{Hg}^{2+}$ 的近红外识别, 在此我们以化合物 79 为例, 简要阐述其具体的识别过程，在甲醇和水的混合体系 中, 化合物 79 在 $660 \mathrm{~nm}$ 处有最大吸收, 苂光发射峰在 $775 \mathrm{~nm}$, 加入 $\mathrm{Hg}^{2+}$ 后发生脱硫反应生成咪唑环, 在光谱 上表现为 $660 \mathrm{~nm}$ 的吸收峰降低, 在 $845 \mathrm{~nm}$ 处出现新的 吸收峰, $775 \mathrm{~nm}$ 的底物荧光峰降低, $830 \mathrm{~nm}$ 处产物的荧 光峰增强(Eq. 18).

\section{8 结论与展望}

通过分子内电荷转移( ICT)、光诱导的电子转移 (PET)、苂光共振能量转移(FRET)、激发态分子内质子 转移(ESIPT)、激基缔合物的生成、螯合作用导致的荧 光增强(CHEF)等不同的苂光传感分子的设计机理，结 合我们自己的部分工作 ${ }^{[75 ~ 80]}$ 归纳总结了近 5 年来相关

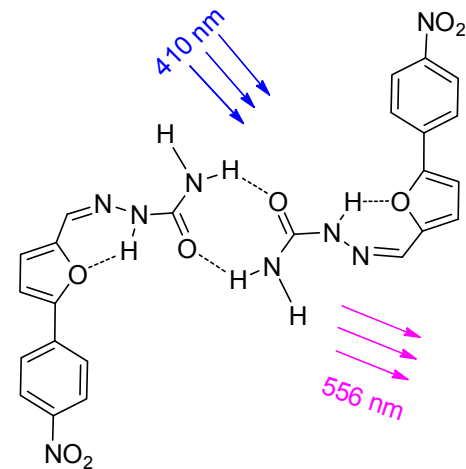


<smiles>Nc1ccc(N=Nc2ccc(N(CCO)CCO)cc2)c(N)c1</smiles>
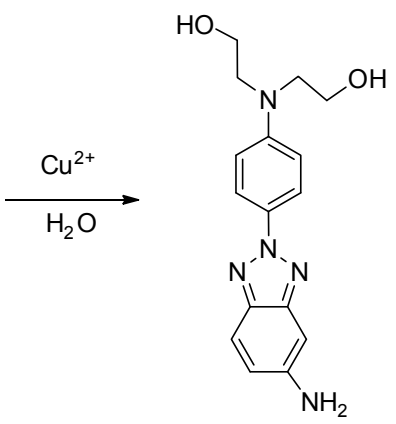

(18)
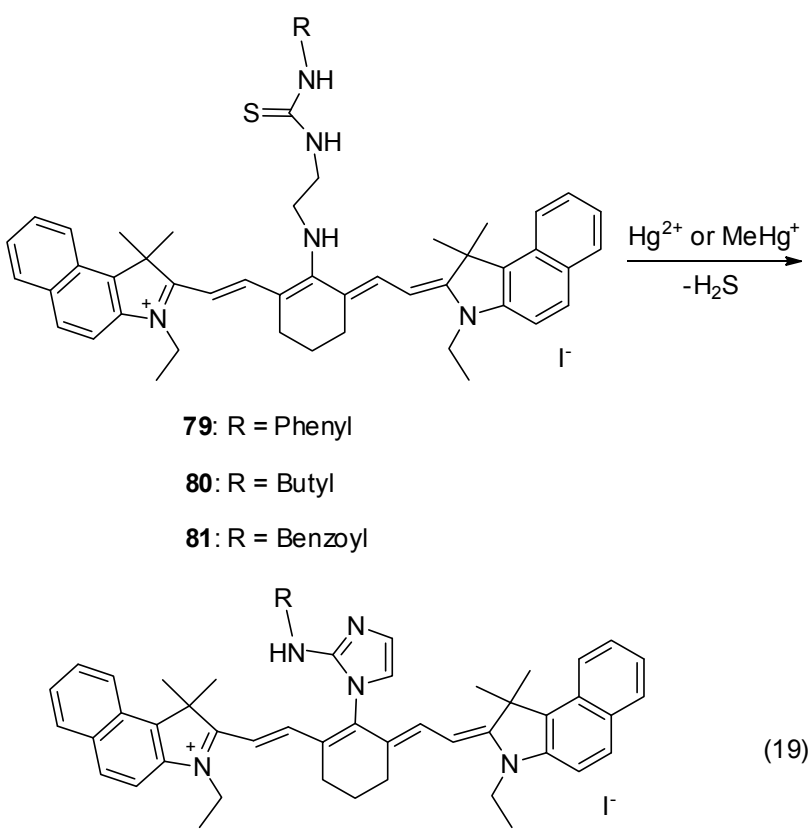

文献报道. 总结文献我们不难发现 ICT 型荧光传感的主 要特征是主体分子设计合成简单, 对金属离子响应敏 感, 荧光光谱变化较为明显, 但难以实现 switch on/off 的开关效果; PET 过程则借助于杂原子的孤对电子对荧 光团的调控实现苂光光谱的开关响应, 但由于杂原子的 配位能力较强, 导致该类受体的选择性较差且易受竞争 离子的干扰; FRET 型荧光传感分子设计条件苛刻, 但 可通过短波长激发实现长波长发射，因而广泛应用于检 测生物体特定阳离子; ESIPT 过程可以有效的降低激发 态分子的光反应可能性并且显著地增强分子的耐光性, 同时产生一个很明显的 Stokes 位移, 该类传感分子设计 要求受体化合物中含有较为活泼的质子(如酚羟基), 且 易于发生互变异构(比如醌酮式与烯醇式转换), 因此 ESIPT 过程容易受到溶剂分子的影响; 激基缔合物的生 成/消失荧光传感分子的设计要求主体分子含有较大平 面的苂光团, 如芸、葱、萠等, 较易通过 $\pi-\pi$ 堆积作用 形成激基缔合物, 该识别过程易受单体浓度和溶剂粘度 的影响, 单体浓度较低时, 通常观察到单体荧光; 单体
浓度足够大，环境利于两个苂光团接近，且激发单体寿 命较长时，容易形成激基缔合物; 鳌合作用导致的菼光 增强机理类似于 PET过程，通过金属离子的配位作用达 到对荧光团的调控. 科研工作者们根据以上介绍的几种 荧光传感机理设计合成了很多性能优异的金属离子响 应型苂光传感分子, 部分产品已经通过苂光成像技术应 用于活细胞中离子的识别检测，但真正商业化还需进一 步完善性能. 今后，具有灵敏度高、选择性高、溶解性 好和光稳定性能好等优点的离子响应型苂光传感分子 的设计合成及应用研究仍然是化学家、生物化学家和环 境科学家研究的热门课题. 如何将相关领域如电子转 移、能量转移以及纳米科学的最新成果应用到离子响应 型荧光传感器的设计和合成, 有着重要的价值和前景. 此外，传统的苂光传感分子的设计方法过分地依赖于经 验而缺乏成熟的理论指导, 如何建立一套有着预测能力 的传感器设计理论, 值得人们进行探索.

\section{References}

[1] Yang, X. B.; Ge, J. F.; Xu, Q. F.; Zhu, X. L.; Li, N. J.; Gu, H. W.; Lu, J. M. Tetrahedron Lett. 2011, 52, 2492.

[2] Chen, H. H.; Chen, Y. Z.; Li, Z. J.; Yang, Q. Z.; Xin, L. Chin. J. Org. Chem. 2012, 32, 46 (in Chinese).

(陈红海, 陈玉哲, 李仲谨, 杨清正, 辛利, 有机化学, 2012, 32, 46.)

[3] Liu, M.; Tan, H. L.; Liu, Z. G.; Wang, W.; Zeng, W. B. Chin. J. Org. Chem. 2013, 33, 1655 (in Chinese).

(刘敏, 谭慧龙, 刘治国, 王维, 曾文涁, 有机化学, 2013, 33, 1655.)

[4] Kim. J. S.; Quang, D. T. Chem. Rev. 2007, 107, 3780.

[5] Yuan, L.; Lin, W. Y.; Zheng, K. B.; Zhu, S. S. Acc. Chem. Res. 2013, 46, 1462.

[6] Jia, J.; Tang, X.; He, Y. F.; Zhang, M. Y.; Xing, G. W. Chin. J. Org. Chem. 2012, 32, 1803 (in Chinese).

(㚘佳，唐茜，何颖芳，张梦雨，邢国文，有机化学，2012，32, 1803.)

[7] Lin, Q.; Chen, P.; Liu, J.; Fu, Y. P.; Zhang, Y. M.; Wei, T. B. Prog. Chem. 2013, 7, 1177 (in Chinese).

(林奇, 陈佩, 刘娟, 符永鹏, 张有明, 魏太保, 化学进展, 2013, 7, 1177.)

[8] Chen, X. Q.; Pradhan, T.; Wang, F.; Kim, J. S.; Yoon, J. Chem. Rev. 2012, 112, 1910.

[9] Qian, F.; Zhang, C. L.; Zhang, Y. M.; He, W. J.; Gao, X.; Hu, P.; Guo, Z. J. J. Am. Chem. Soc. 2009, 131, 1460.

[10] Goswami, S.; Sen, D.; Das, N. K. Org. Lett. 2010, 12, 856.

[11] Zhu, M.; Yuan, M. J.; Liu, X. F.; Xu, J. L.; Lv, J.; Huang, C. S.; Liu, H. B.; Li, Y. L.; Wang, S.; Zhu, D. B. Org. Lett. 2008, 10, 1481.

[12] Taki, M.; Desaki, M.; Ojida, A.; Iyoshi, S.; Hirayama, T.; Hamachi, I.; Yamamoto, Y. J. Am. Chem. Soc. 2008, 130, 12564.

[13] Debabrata, M.; Govindaraju, T. Inorg. Chem. 2010, 49, 7229.

[14] Li, Q. Q.; Peng, M.; Li, H. Y.; Zhong, C.; Zhang, L.; Cheng, X. H.; Peng, X. N.; Wang, Q. Q.; Qin, J. G.; Li, Z. Org. Lett. 2012, 14, 2094.

[15] Jiang, J.; Liu, W.; Cheng, J.; Yang, L. Z.; Jiang, H. E.; Bai, D. C.; Liu, W. S. Chem. Commun. 2012, 48, 8371. 
[16] Feng, X. J.; Tian, P. Z.; Xu, Z.; Chen, S. F.; Wong, M. S. J. Org. Chem. 2013, 78, 11318.

[17] Goswami, S.; Sen, D.; Aich, K. Tetrahedron Lett. 2013, 54, 4620.

[18] Chen, X. F.; Wang, J, Y.; Cui, J. N.; Xu, Z. C.; Peng, X. J. Tetrahedron 2011, 67, 4869.

[19] Hatai, J.; Pal, S.; Jose, G. P.; Bandyopadhyay, S. Inorg. Chem. 2012, 51, 10129.

[20] Helal, A.; Rashid, M. H.; Choi, C. H.; Kim, H. S. Tetrahedron 2011, 67, 2794.

[21] Lohani, C. R.; Kim, J. M.; Lee, K. H. Tetrahedron 2011, 67, 4130.

[22] He, H.; Ng, D. K. P. Chem. Asian J. 2013, 8, 1441.

[23] Zhang, Y. M.; Shi, B. B.; Zhang, P.; Huo, J. Q.; Chen, P.; Lin, Q.; Liu, J.; Wei, T. B. Sci. China Chem. 2013, 56, 612.

[24] Lin, Q.; Liu, X.; Wei, T. B.; Zhang, Y. M. Sens. Actuators, B 2014, 190, 459.

[25] Cheng, T. Y.; Xu, Y. F.; Zhang, S. Y.; Zhu, W. P.; Qian, X. H.; Duan, L. P. J. Am. Chem. Soc. 2008, 130, 16160.

[26] Cheng, T. Y.; Wang, T.; Zhu, W. P.; Chen, X. L.; Yang, Y. J. Xu, Y. F.; Qian, X. H. Org. Lett. 2011, 13, 3656.

[27] Yang, Y. Y.; Cheng, T. Y.; Zhu, W. P.; Xu, Y. F.; Qian, X. H. Org. Lett. 2011, 13, 264.

[28] Dodani, S. C.; Leary, S. C.; Cobine, P. A.; Winge, D. R.; Chang, C. J. J. Am. Chem. Soc. 2011, 133, 8606.

[29] Taki, M.; Akaoka, K.; Iyoshi, S.; Yamamoto, Y. Inorg. Chem. 2012, 51, 13075.

[30] Zheng, H.; Yan, M.; Fan, X. X.; Sun, D.; Yang, S. Y.; Yang, L. J.; Li, J. D.; Jiang, Y. B. Chem. Commun. 2012, 48, 2243.

[31] Suresh, M.; Mandal, A. K.; Saha, S.; Suresh, E.; Mandoli, A.; Liddo, R. D.; Parnigotto, P. P.; Das, A. Org. Lett. 2010, 12, 5406.

[32] Mandal, A. K.; Suresh, M.; Das, P.; Suresh, E.; Mithu, B.; Ghosh, S. K.; Das, A. Org. Lett. 2012, 14, 2980.

[33] Neupane, L. N.; Park, J. Y.; Park, J. H.; Lee, K. H. Org. Lett. 2013, $15,254$.

[34] Kim, J.; Oka, Y.; Morozumi, T.; Choi, E. W.; Nakamura, H. Tetrahedron 2011, 67, 4814.

[35] Mahato, P.; Saha, S.; Suresh, E.; Liddo, R. D.; Parnigotto, P. P.; Conconi, M. T.; Kesharwani, M. K.; Ganguly, B.; Amitava, D. Inorg. Chem. 2012, 51, 1769.

[36] Chirantan, K.; Adhikari, M. D.; Ramesh, A.; Das, G. Inorg. Chem. 2013, 52, 743 .

[37] Kesavapillai, S.; Clark, R. J.; Zhu, L. J. Org. Chem. 2012, 77, 8268.

[38] Chu, K. H.; Zhou, Y.; Fang, Y.; Wang, L. H.; Li, J. Y.; Yao, C. Dyes Pigm. 2013, 98, 339.

[39] Zhou, X.; Yan, W.; Zhao, T.; Tian, Z. X.; Wu, X. Tetrahedron 2013, 69, 9535 .

[40] Hu, X. Y.; Zhang, X. L.; He, G. J.; He, C.; Duan, C. Y. Tetrahedron 2011, 67, 1091.

[41] Delbaere, S.; Tulyakova, E. V.; Marmois, E.; Jonusauskas, G.; Gulakova, E. N.; Fedorov, Y. V.; Fedorova, O. A. Tetrahedron 2013, 69,8178 .

[42] Fang, G.; Xu, M. Y.; Zeng, F.; Wu, S. Z. Langmuir 2010, 26, 17764.

[43] Yuan, L.; Lin, W. Y.; Chen, B.; Xie, Y. N. Org. Lett. 2012, 14, 432.

[44] Santra, M.; Roy B.; Ahn, K. H. Org. Lett. 2011, 13, 3422.

[45] Iniya, M.; Jeyanthi, D.; Krishnaveni, K.; Mahesh, A.; Chellappa, D. Spectrochim. Acta, Part A 2014, 120, 40.

[46] Goswami, S.; Das, S.; Aich, K.; Sarkar, D.; Mondal, T. K. Tetrahedron Lett. 2013, 54, 6892.

[47] Kim, M. J.; Kaur, K.; Singh, N.; Jang, D. O. Tetrahedron 2012, 68, 5429.

[48] Helal, A.; Rashid, M. H. O.; Choi, C. H.; Kim, H. S. Tetrahedron 2012, 68, 647
[49] Chen, W. H.; Xing, Y.; Pang, Y. Org. Lett. 2011, 6, 1362.

[50] Gao, G. Y.; Qu, W. J.; Shi, B. B.; Zhang, P.; Lin, Q.; Yao, H.; Yang, W. L.; Zhang, Y. M.; Wei, T. B. Spectrochim. Acta, Part A 2014, 121, 514.

[51] Kwon, J. E.; Lee, S.; You, Y. M.; Baek, K. H.; Kei, O.; Cho, J.; Fukuzumi, S.; Shin, I.; Park, S. Y.; Nam, W. Inorg. Chem. 2012, 51,8760 .

[52] Banerjee, A.; Sahana, A.; Guha, S.; Lohar, S.; Hauli, I.; Mukhopadhyay, S. K.; Matalobos, J. S.; Debasis, D. Inorg. Chem. 2012, $51,5699$.

[53] Yang, M. H.; Thirupathi, P.; Lee, K. H. Org. Lett. 2011, 13, 5028.

[54] Zhou, Y.; Zhu, C. Y.; Gao, X. S.; You, X. Y.; Yao, C. Org. Lett. 2010, 12, 2566.

[55] Wang, F.; Nandhakumar, R.; Moon, J. H.; Kim, K. M.; Lee, J. Y.; Yoon, J. Inorg. Chem. 2011, 50, 2240.

[56] Lin, W. Y.; Yuan, L.; Feng, J. B. Eur. J. Org. Chem. 2008, 73, 3821.

[57] Zhou, Y.; Li, Z. X.; Zang, S. Q.; Zhu, Y. Y.; Zhang, H. Y.; Hou, H. W.; Thomas, C. W. M. Org. Lett. 2012, 14, 1214.

[58] Jang, S. J.; Ponnaboina, T.; Lok, N. N.; Junho, S.; Hyunsook, L.; Wan, I. L.; Lee, K. H. Org. Lett. 2012, 14, 4746.

[59] Ding, Y. B.; Li, X.; Li, T.; Zhu, W. H.; Xie, Y. S. J. Org. Chem. 2013, 78, 5328.

[60] Shen, K.; Yang, X.; Cheng, Y. X.; Zhu, C. J. Tetrahedron 2012, 68, 5719.

[61] Arturo, J. S.; Norberto, F.; Rosa, S. Tetrahedron Lett. 2013, 54 5279 .

[62] Wei, T. B.; Zhang, P.; Shi, B. B.; Chen, P.; Lin, Q.; Liu, J.; Zhang, Y. M. Dyes Pigm. 2013, 97, 297.

[63] Kumar, M.; Kumar, N.; Bhalla, V.; Singh, H.; Sharma, P. R.; Kaur, T. Org. Lett. 2011, 13, 1422.

[64] Fan, J. L; Zhan, P.; Hu, M. M.; Sun, W.; Tang, J. Z.; Wang, J. Y.; Sun, S. G.; Song, F. L.; Peng, X. J. Org. Lett. 2013, 15, 492.

[65] Lin, Q.; Liu, X.; Wei, T. B.; Zhang, Y. M. Chem. Asian J. 2013, 8, 3015.

[66] Zhang, P.; Shi, B. B.; Wei, T. B.; Zhang, Y. M.; Lin, Q.; Yao, H.; You, X. M. Dyes Pigm. 2013, 99, 857.

[67] Lin, Q.; Fu, Y. P.; Chen, P.; Wei, T. B.; Zhang, Y. M. Tetrahedron Lett. 2013, 54, 5031.

[68] Zhang, P.; Shi, B. B.; You, X. M.; Zhang, Y. M.; Lin, Q.; Yao, H.; Wei, T. B. Tetrahedron 2014, 70, 1889.

[69] Lin, Q.; Zhu, X.; Chen, P.; Fu, Y. P.; Zhang, Y. M.; Wei, T. B. Acta Chim. Sinica 2013, 71, 1516 (in Chinese). (林奇, 朱金鍂, 佩, 符永鹏, 张有明, 魏太保, 化学学报, 2013, $71,1516$.

[70] Shi, B. B.; Zhang, P.; Wei, T. B.; Yao, H.; Lin, Q.; Zhang, Y. M. Chem. Commun. 2013, 49, 7812.

[71] Luo, F.; Chen, D. M.; Shi, Y. M.; Chen, X. Sci. China Chem. 2013, 43, 592 (in Chinese). (罗峰, 陈冬梅, 施雅梅, 陈曦, 中国科学: 化学, 2013, 43, 592.)

[72] Zhang, P.; Shi, B. B.; Zhang, Y. M.; Lin, Q.; Yao, H.; You, X. M.; Wei, T. B. Tetrahedron 2013, 69, 10292.

[73] Jo, J.; Lee, H. Y.; Liu, W. J.; Olasz, A.; Chen, C. H.; Lee, D. J. Am. Chem. Soc. 2012, 134, 16000.

[74] Guo, Z. Q.; Zhu, W. H.; Zhu, M. M.; Wu, X. M.; Tian, H. Chem. Eur. J. 2010, 16, 14424.

[75] Liu, J.; Xie, Y. Q.; Lin, Q.; Shi, B. B.; Zhang, P.; Zhang, Y. M.; Wei, T. B. Sen. Actuators, B 2013, 186, 657.

[76] Shi, B. B.; Zhang, Y. M.; Wei, T. B.; Lin, Q.; Yao, H.; Zhang, P.; You, X. M. Sen. Actuators, B 2014, 190, 555.

[77] Shi, B. B.; Zhang, P.; Wei, T. B.; Yao, H.; Lin, Q.; Liu, J.; Zhang, Y. M. Tetrahedron 2013, 69, 7981. 
[78] Shi, B. B.; Zhang, Y. M.; Wei, T. B.; Zhang, P.; Lin, Q.; Yao, H. New J. Chem. 2013, 37, 3737.

[79] Liu, J.; Lin, Q.; Zhang, Y. M.; Wei, T. B. Sen. Actuators, B 2014,
196, 619.

[80] Wei, T. B.; Liu, J.; Yao, H.; Xie, Y. Q.; Shi, B. B.; Zhang, P.; You, X. M.; Zhang, Y. M. Chin. J. Chem. 2013, 31, 515.

(Zhao, C.) 